\title{
Treatment optimization of locally advanced and metastatic pancreatic cancer (Review)
}

\author{
ANABELA G. BARROS ${ }^{1}$, CATARINA F. PULIDO ${ }^{2}$, MANUELA MACHADO $^{3}$, MARIA JOSÉ BRITO $^{4}$,

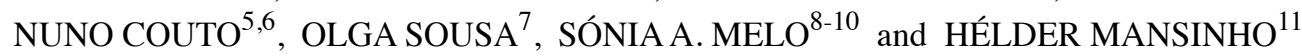

\author{
${ }^{1}$ Department of Medical Oncology, University Hospital of Coimbra, 3004-561 Coimbra; ${ }^{2}$ Department of Medical Oncology, \\ Luz Lisbon Hospital, 1500-650 Lisbon; ${ }^{3}$ Department of Medical Oncology, Entre o Douro e Vouga Hospital Center (CHEDV), \\ 4520-211 Santa Maria da Feira; ${ }^{4}$ Pathologic Anatomy Department, Garcia de Orta Hospital, 2805-267 Almada; \\ ${ }^{5}$ Digestive Unit, Champalimaud Clinical Centre; ${ }^{6}$ Champalimaud Research Centre, 1400-038 Lisbon; \\ ${ }^{7}$ Radiotherapy Department, Portuguese Institute of Oncology, 4200-072 Porto; 8 i3S-Institute for Research and \\ Innovation in Health of University of Porto; ${ }^{9}$ IPATIMUP-Institute of Molecular Pathology and Immunology \\ of University of Porto, 4200-135 Porto; ${ }^{10}$ Faculty of Medicine, University of Porto, 4200-319 Porto; \\ ${ }^{11}$ Hemato-Oncology Department, Garcia de Orta Hospital, 2805-267 Almada, Portugal
}

Received June 11, 2021; Accepted October 12, 2021

DOI: $10.3892 / \mathrm{ijo} .2021 .5290$

\begin{abstract}
Pancreatic ductal adenocarcinoma (PDAC) is one of the most lethal malignant tumor types, being the sixth leading cause of mortality worldwide and the fourth in Europe. Globally, it has a mortality/incidence ratio of $98 \%$, and the 5 -year survival rate in Europe is only 3\%. Although risk factors, such as obesity, diabetes mellitus, smoking, alcohol consumption and genetic factors, have been identified, the causes of PDAC remain elusive. Additionally, the only curative treatment
\end{abstract}

Correspondence to: Dr Hélder Mansinho, Hemato-Oncology Department, Garcia de Orta Hospital, Avenue Torrado da Silva, 2805-267 Almada, Portugal

E-mail: heldermansinho@gmail.com

Abbreviations: 5-FU, 5-fluorouracil; AE, adverse effect; ALK, anaplastic lymphoma kinase; ASCO, American Society of Clinical Oncology; BSC, best supportive care; CAP, capecitabine; CA 19.9, cancer antigen 19.9; CT, chemotherapy; DM, diabetes mellitus; ECOG, European Cooperative Oncology Group; EGFRs, epidermal growth factor receptors; ESMO, European Society for Medical Oncology; FA, folinic acid and leucovirin; HR, hazard ratio; MMR, mismatch-repair; MSI, microsatellite instability; NCCN, National Comprehensive Cancer Network; NTRK, neutrophic-tropomyosin receptor kinase; ORR, overall response rate; OS, overall survival; PanIN, pancreatic intraepithelial neoplasia; PARP, poly adenosine diphosphate-ribose polymerase; PDAC, pancreatic ductal adenocarcinoma; PFS, progression-free survival; PS, performance status; QOL, quality of life; RCTs, randomized controlled trial; RR, relative risk; RT, radiation therapy; SBRT, stereotactic body radiation therapy; TRK, tropomyosin receptor kinases; ULN, upper limit of normal

Key words: pancreatic cancer, epidemiology, risk factors, palliative, treatment guidelines, clinical trials for PDAC is surgery with negative margins. However, upon diagnosis, $30 \%$ of the patients already present with locally advanced disease. In these cases, a multidisciplinary approach is required to improve disease-related symptoms and prolong patient survival. In the present article, a comprehensive review of PDAC epidemiology, physiology and treatment is provided. Moreover, guidelines on patient treatment are suggested. Among the different available therapeutic options for the treatment of advanced PDAC, results are modest, most likely due to the complexity of the disease, and so the prognostic remains poor. Molecular approaches based on multi-omics research are promising and will contribute to groundbreaking personalized medicine. Thus, economic investment that promotes research of pancreatic cancer will be critical to the development of more efficient diagnostic and treatment strategies.

\section{Contents}

1. Introduction

2. Pathogenesis

3. Treatment of patients with borderline resectable and locally advanced tumors

4. Options in the treatment of metastatic disease

5. New therapeutic targets and biomarkers

6. Conclusion

\section{Introduction}

Epidemiology. Pancreatic ductal adenocarcinoma (PDAC) is the sixth leading cause of mortality worldwide and the fourth in Europe. In 2018, 458,918 and 132,559 new cases were diagnosed worldwide and in Europe, with 432,242 and 128,000 deaths, respectively (1). Observed trends in pancreatic cancer mortality rates in Europe are stable or slightly increasing, and 
the number of deaths caused by pancreatic cancer is expected to increase with the continuous ageing of the European population (1). At present, survival rates for pancreatic cancer are not improving in Europe and are unequal in different European countries. Fig. 1 represents the estimated age-standardized rates of pancreatic cancer incidence (blue bars) and mortality (red bars) in 2020. Data from Globocan (2) shows that the gaps between the countries are substantial. For example, both the incidence and mortality rates in Albania and Portugal are the lowest, as opposed to Hungary and Czech Republic with one of the highest incidence and mortality rates (3). These discrepancies may be attributed to distinct genetic and cultural backgrounds, as well as exposure to diverse environmental risk factors and different reporting methods. Diagnosis and access to new treatment options could also contribute to variations among different countries. The high incidence rate in Europe, with $30.7 \%$ of the global incidence, can reflect not only the epidemiology but also the ability for diagnosis and the diagnostic approach $(2,4)$.

PDAC is predominantly a disease affecting elderly individuals $(5,6)$. Its incidence peaks at $>70$ years, and almost $90 \%$ of cases are diagnosed after the age of 55 years $(5,6)$. As expected, due to PDAC being one of the most fatal malignant tumor types, the mortality/incidence ratio is $98 \%(2,6)$. In Europe, 1-year survival rates range from 10 to $23 \%$ and the 5-year survival rate is $3 \%$ (7).

At present, since there is no established screening for early detection, and the causes of pancreatic cancer remain elusive, primary prevention is of the utmost importance for reducing PDAC burden $(6,8)$.

Risk factors. Epidemiological studies have suggested different modifiable risk factors for PDAC, including overweight and obesity $(8,9)$, physical inactivity $(10)$, smoking $(11,12)$, alcohol consumption $(13,14)$ and diabetes mellitus (DM) $(15)$, as well as non-modifiable risk factors, such as age (16), chronic pancreatitis $(13,14)$ and genetic factors/family history of PDAC (17,18). A previous systematic review and meta-analysis of 23 prospective studies including 9,504 patients revealed that a BMI $>25 \mathrm{~kg} / \mathrm{m}^{2}$ and high waist circumference increase the risk of pancreatic cancer (8).

Smoking is a well-established modifiable risk factor for PDAC (11). Nevertheless, it accounts for $<30 \%$ of the PDAC incidence (15). In total, 82 cohort and case control studies published between 1950 and 2007 reported a relative risk (RR) of 1.7 (95\% CI, 1.6-1.9) for current smokers and 1.2 (95\% CI, 1.1-1.3) for former smokers, with the risk being maintained 10 years after smoking cessation (12).

The association of DM with PDAC is widely recognized. A meta-analysis of 35 cohort studies, published in 2011, showed that DM was associated with an increased risk of PDAC ( $\mathrm{RR}=1.94 ; 95 \% \mathrm{CI}, 1.66-2.27)$. These authors concluded that this risk occurs in both sexes and that DM is considered both as an early manifestation and an etiologic factor for PDAC (15).

Chronic pancreatitis is a well-known risk factor for PDAC, although it can also be a consequence of the tumor due to duct obstruction. A pooled analysis from the International Pancreatic Cancer Case-Control Consortium demonstrated an association between pancreatitis and PDAC (13). Mutations in the cationic trypsinogen gene, serine protease 1 and in the serine protease inhibitor gene (serine peptidase inhibitor Kazal type 1) cause autosomal dominant and recessive forms of hereditary pancreatitis, respectively (19-21). Patients with hereditary pancreatitis have a 58-fold (95\% CI, 23-105) increased risk of developing PDAC compared with those without (22).

A pooled analysis from the Pancreatic Cancer Cohort Consortium examined the association between family history of cancer (pancreatic, prostate, ovarian, breast and colorectal) and the risk of PDAC (17), and only a family history of PDAC or prostate cancer were found to be associated with an increased risk of PDAC.

Inherited conditions, such as familial Peutz-Jeghers syndrome, confer very high relative risk for gastrointestinal cancer types, namely PDAC (23). Germline mutations in $B R C A 1$ and BRCA2 also predispose to PDAC. For instance, women that carry mutations in these genes have twice the risk of PDAC compared with the women without BRCAl and $B R C A 2$ mutations (24). Another inherited associated condition of PDAC is Lynch syndrome caused by mutations in DNA mismatch repair (MMR) genes, which shows a cumulative risk of PDAC of $1.13 \%$ (95\% CI, $0.31-2.32 \%$ ) at $<50$ years of age and $3.68 \%(95 \%$ CI, $1.45-5.88 \%)$ at $<70$ years of age (25). Other genetic alterations have been associated with an increased risk of developing PDAC. For example, deletion of P16 (p16-Leiden) carriers have a 17\% lifetime (by the age of 75 years) risk of developing pancreatic cancer, and a mutation in $P 16 / C D K N 2 A$ leads to a 38 -fold increased risk of developing PDAC and TP53 germline mutations (18,26-29).

\section{Pathogenesis}

Pancreatic cancer types are usually adenocarcinomas from the exocrine part of the gland, but a minority represents neuroendocrine tumors arising from the endocrine pancreas. In most cases PDAC is the result of cumulative genetic alterations from precursor lesions, pancreatic intraepithelial neoplasia (PanIN), that are microscopic $(<5 \mathrm{~mm})$ and arise from pancreatic ducts. PanIN1 represents mucinous differentiation of the ductal cells with minimal atypia, and PanIN3 corresponds to carcinoma in situ. The average time between the two grades could be 11.7 years $(30,31)$. Fig. 2 schematically depicts the evolution of PDAC.

From a pathology standpoint there are classical key characteristics of PDAC that contribute to its aggressiveness and poor prognosis, such as the type of pre-cancer lesions, stage at diagnosis, including lymph node $\left(\mathrm{N}^{+}\right)$metastases, metastatic spread, cell proliferation and programmed cell death, genetic signature, cellular differentiation, epithelialmesenchymal interaction, characteristics of the tumor stroma, immune response, perineural invasion and cancerization of ducts $(30,31)$. Another component, venous invasion, may have importance in this context. In fact, $2 / 3$ of patients with PDAC who underwent surgical resection had identifiable venous invasion $(32,33)$, which could explain the rapid dissemination to the liver.

The aggressiveness of PDAC has also been associated with a complex genomic landscape (including frequent copy number changes and point mutations, as well as SMAD4 loss), the release of exosomes by the neoplastic cells, which facilitates 


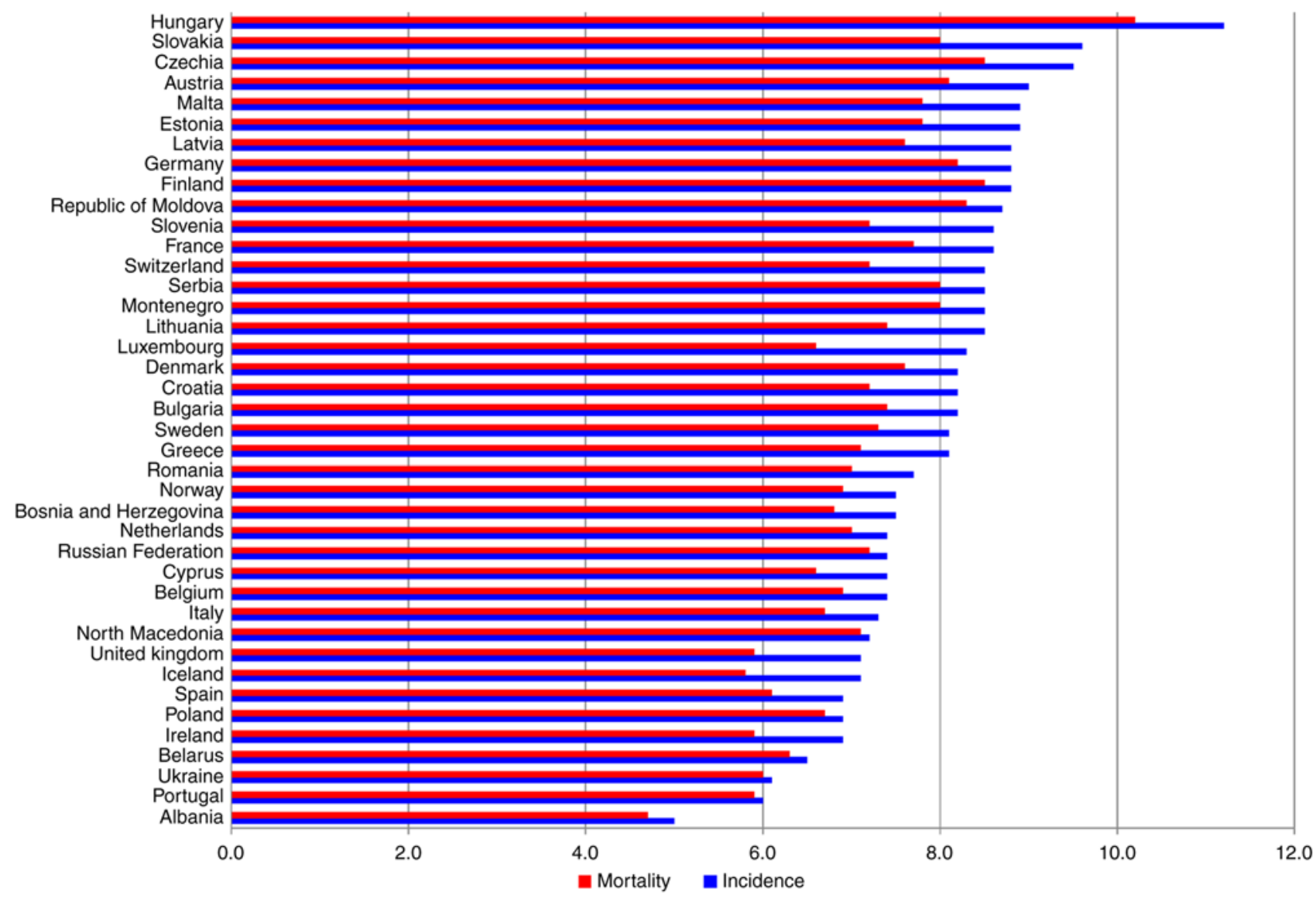

Figure 1. Estimated age-standardized rates of pancreatic cancer incidence and mortality in Europe in 2020. Data from Globocan 2020 (3).

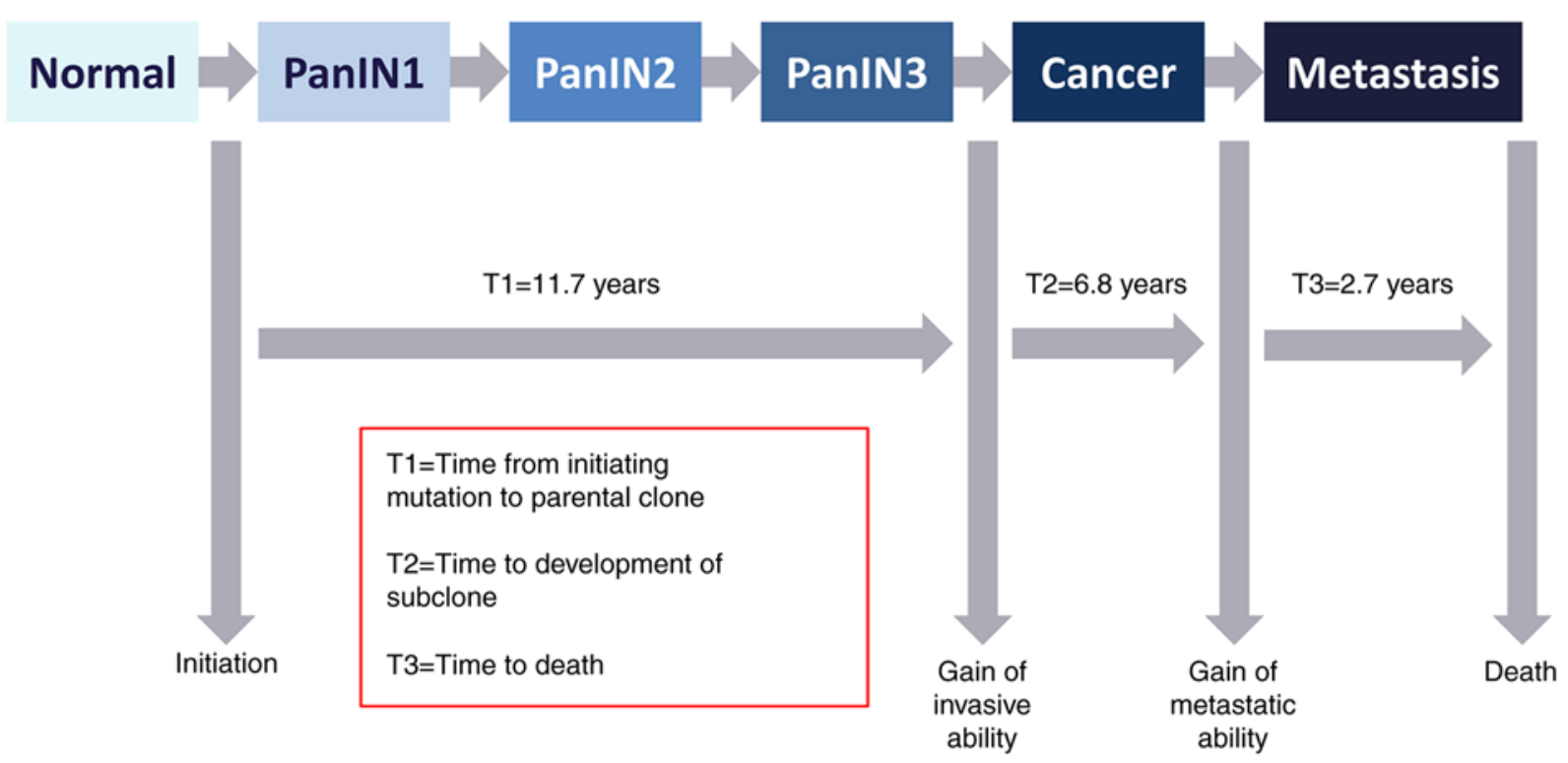

Figure 2. Schematic representation of the evolution of pancreatic ductal adenocarcinoma. Adapted from (31). yrs, years.

liver metastasis (34), the 'seed and soil' hypothesis and the presence of circulating tumor cells. The seed and soil hypothesis states that metastatic tumor cells will metastasize to a site where the local microenvironment is favorable and that the mechanical process of metastization is determined by the pattern of blood flow containing circulating tumor cells (35).
Although cancer gene amplification mainly occurs in the earlier disease phases, genomic instability is maintained throughout the different steps of the metastatic cascade, and the genetic heterogeneity found in the different sites of metastases may stem from the primary non-metastatic tissue, since the distinct clones are shown to be already present in this 
Table I. National Comprehensive Cancer Network classification of locally advanced PDAC (40).

Classification criteria of locally advanced PDAC
Borderline resectable
Unresectable

\begin{tabular}{ll}
\hline SMA & Tumor abutment $\leq 180^{\circ}$ \\
CHA & Reconstructible short segment abutment
\end{tabular}

CA SMV-PV
Tumor without encasement/abutment

Tumor abutment of SMV/PV of $>180^{\circ}$ or abutting $\leq 180^{\circ}$ with irregularity of the vein \pm thrombosis with anatomical structures that still allow for safe, complete resection and vein reconstruction

\begin{abstract}
Solid tumor contact of $>180^{\circ}$
Contact with extension to CA or hepatic artery bifurcation

Solid tumor contact of $>180^{\circ}$ or any contact with aortic involvement Unreconstructible due to tumor involvement or occlusion, or contact with most proximal draining jejunal branch into SMV (can be due to tumor or bland thrombus)
\end{abstract}

SMA, superior mesenteric artery; CHA, common hepatic artery; CA, celiac axis; SMV, superior mesenteric vein; PV, portal vein.

tissue. Thus, early genomic events in the tumor evolution can determine the later molecular subtypes of PDAC (36).

Even though the different molecular subtypes are the result of intra-tumoral subpopulations, there are recurrent mutations that occur in KRAS, CDKN2A, TP53 and SMAD4 pathways (37-40). These mutations appear to occur after pre-neoplastic changes, which helps to explain the different invasive phenotypes of PDAC. Although PDAC has been divided in two subtypes, basal-like and classic, detailed genomic and transcriptomic analyses have revealed that even within these subtypes there is heterogeneity (38).

\section{Treatment of patients with borderline resectable and locally advanced tumors}

The only curative treatment for PDAC is surgery with negative margins. However, up to $30 \%$ of patients have locally advanced disease at diagnosis and are not eligible for potentially curative surgery (6). Patients with locally advanced PDAC have an intermediate prognosis between resectable and metastatic disease, with a median overall survival (OS) of 9-11 months (41). The classification of locally advanced PDAC is summarized in Table I.

The treatment approach, based on these criteria, should be decided at multidisciplinary meetings (42). Moreover, due to the difficulty of strict criteria of unresectability, to clearly differentiate between locally advanced and borderline resectable tumors it should be recommended that all cases of non-metastatic tumors are discussed by a multidisciplinary team after induction therapy to confirm definitive unresectability (43). Some key concepts used in this setting do not have a universal definition, and so it is important to clarify that henceforth the term 'induction chemotherapy (CT)' will be used referring to the CT administered before radiotherapy as part of a standard set of treatments (including CT, followed by radiation and eventually surgery), and neoadjuvant $\mathrm{CT}$ will be used referring to the $\mathrm{CT}$ administered before surgery as a first step to shrink the tumor before the main treatment with curative intent (44-46).

At present, the therapeutic strategy for locally advanced PDAC is not optimized. The CT regimens applied in this setting are based on data from trials with patients with metastatic disease, with the selection between mFOLFIRINOX or gemcitabine + nab-paclitaxel (GEM/nab-P) being determined by availability and risk profile. The only consensus is that patients without surgical indication should receive CT (46).

Another challenge is neoadjuvant therapy. FOLFIRINOX or GEM/nab-P have been evaluated in this context $(47,48)$. The efficacy of FOLFIRINOX and GEM/nab-P was determined in the neoadjuvant setting in a multicenter study including 274 patients with borderline resectable (46.4\%) and locally advanced (25.5\%) pancreatic cancers. The results demonstrated that both neoadjuvant chemotherapy regimens improved biochemical, pathological and clinical responses, leading to OS improvement (48). Another retrospective study also evaluated the efficacy of FOLFIRINOX or GEM/nab-P in the neoadjuvant setting in 56 patients with locally advanced PDAC. Among the 35 patients treated with FOLFIRINOX and the 21 treated with GEM/nab-P, 14 (40\%) and 6 (28\%) patients, respectively, underwent surgery after CT. It was found that disease-free survival in resected patients was not statistically different between the two treatments. In the unresected group, the progression-free survival (PFS) was 49.4 weeks with FOLFIRINOX and was 30.9 weeks with GEM/nab-P $(\mathrm{P}=0.0029)$, whilst the median OS was 72.10 weeks with FOLFIRINOX and 53.30 weeks with GEM/nab-P $(\mathrm{P}=0.06)$. In the resected group, after a follow-up of $>12$ months, the median OS was not reached in the FOLFIRINOX group and was $~ 93.79$ weeks in GEM/nab-P group. These differences were significant when compared with the unresectable patients $(\mathrm{P}=0.0006$ in the FOLFIRINOX group; $\mathrm{P}=0.0166$ in the GEM/nab-P group). These results indicated that, even in patients who did not undergo surgery, there was a gain in PFS. However, although neoadjuvant therapy plus surgery is valuable, there is a need for a long-term follow-up (47).

In the American Society of Clinical Oncology (ASCO) 2020 meeting, an important trial was presented, which was the ESPAC-5F trial, a four-arm prospective phase II trial of immediate surgery compared with neoadjuvant GEM/capecitabine (CAP), FOLFIRINOX or chemoradiotherapy in patients with borderline resectable pancreatic cancer. This trial showed 
that this group of patients had a survival advantage from neoadjuvant therapy (12 months survival of $40 \%$ for immediate surgery vs. $77 \%$ in the neoadjuvant treatment) (49). These data, referring to patients considered to have resectable disease at diagnosis lend additional support to the use of a neoadjuvant approach for advanced disease, although doubts remain regarding the best therapy regimen. Regardless of these aforementioned results, further research is necessary to understand which factors could predict response, perioperative outcomes and survival in patients submitted to induction CT. A recent study revealed that, in both borderline and locally advanced PDAC, an extended duration of CT with associated biochemical and pathological responses was highly predictive of postoperative survival (50). Modifying the initial CT regimen and/or extending treatment duration until the normalization of cancer antigen 19.9 (CA 19.9) or achieving complete metabolic response may be beneficial. These factors may improve survival despite the limited radiological response, which is mandatory before surgery. Overall, it is crucial to complete the most appropriate chemotherapy (50).

It can be concluded that both FOLFIRINOX and GEM/nab-P could be proposed as induction therapy to patients with locally advanced PDAC and in the neoadjuvant setting for unresectable or borderline resectable cases. Furthermore, in some patients, they can be used in sequence with or without radiotherapy, which corresponds to a total neoadjuvant approach (47,51).

Although different clinical trials are aiming to address the impact of chemoradiotherapy in locally advanced PDAC, its use remains controversial (52-55). LAP07 was an open-label phase III trial that evaluated the effect of chemoradiotherapy (54 Gy plus CAP) vs. CT (same regimen as the initial 4 months) after 4 months of GEM with or without erlotinib in locally advanced PDAC. This trial reported no differences in OS between groups, including chemoradiotherapy vs. CT and GEM alone or GEM/erlotinib as maintenance therapy. However, the chemoradiotherapy group experienced a decrease in local progression (32 vs. 46\%, $\mathrm{P}=0.03$ ) (52).

The SCALOP study was a multicenter phase II study designed to evaluate the safety and efficacy of GEM-based and CAP-based chemoradiation in 74 patients with locally advanced PDAC. Patients underwent a 12-week induction period with GEM/CAP, and patients with stable/responsive disease, tumor $\leq 6 \mathrm{~cm}$ and performance status (PS) 0-1 were randomized to receive one additional cycle of CAP or GEM with radiation (50.4 Gy in 28 fractions) (55). The first results suggested that not only was the CAP-based regimen preferable to the GEM-based regimen after the induction phase, it was also more well tolerated. Notwithstanding, the difference in the 9-month PFS, the primary endpoint, was not statistically significant (55). Long-term results of the SCALOP study revealed that the CAP-based chemoradiation was superior regarding OS and PFS. These long-term results also showed that patients with CA $19.9<46 \mathrm{IU} / \mathrm{ml}$ were more likely to benefit from chemoradiation following the induction phase (54).

The Association des Gastro-Entérologues Oncologues group recently published the data of a retrospective non-randomized study including 203 patients with borderline or locally advanced PDAC. This study evaluated the impact of the addition of neoadjuvant chemoradiotherapy to a FOLFIRINOX induction regimen, and showed a significantly higher $\mathrm{R} 0$ resection rate $(89.2$ vs. $76.3 \%$; $\mathrm{P}=0.017)$, and increased downstaging and OS (57.8 vs. 35.5 months; $\mathrm{P}=0.007$ ), suggesting that additional chemoradiotherapy may be beneficial in the neoadjuvant setting (56).

The ALLIANCE A021501 study randomized patients with borderline resectable pancreatic cancer to either eight cycles of preoperative mFOLFIRINOX or seven cycles of preoperative mFOLFIRINOX, followed by stereotactic body radiation therapy (SBRT). The results demonstrated that neoadjuvant mFOLFIRINOX was associated with favorable OS. Moreover, mFOLFIRINOX with hypofractionated radiation therapy (RT) did not improve OS compared with the historical data (57).

The use of SBRT in locally advanced PDAC has been attempted. Compared with conventional fractionated radiation, SBRT appears to have a limited role in this stage of PDAC. Although the results of a retrospective study that matched 631 patients undergoing SBRT with 7819 patients undergoing conventional fractionated radiotherapy demonstrated that SBRT was associated with an improvement in OS (58), further studies are required to evaluate the precise role of this new therapeutic option.

After neoadjuvant therapy some patients will become surgical candidates and resection will be possible. Nevertheless, for patients with an inadequate response to neoadjuvant CT, radiotherapy could be added to increase the probability of resection in locally advanced or borderline resectable tumors. This is a case-by-case decision, and every patient must be discussed after each therapy modality in a multidisciplinary board. Currently, the role of radiotherapy in PDAC is not conclusively established. However, novel RT techniques and the combination with systemic therapy remain an active area of research.

\section{Options in the treatment of metastatic disease}

Multidisciplinary collaboration is standard in the care of patients with metastatic pancreatic cancer. The treatment goals are to improve disease-related symptoms and prolong survival. Since the currently available therapy is palliative and not curative, additional clinical trials should be performed (59). Early initiation of palliative care, alongside with disease-modifying treatment, should be considered, especially for patients with high symptom burden. The European Cooperative Oncology Group (ECOG) scale relating to patient PS, comorbidity profile, nutritional status, patient preferences, symptom burden and psychosocial issues should guide treatment decision (60).

First line setting. Several trials and meta-analyses demonstrated that CT, mainly 5-fluorouracil (5-FU), is superior to isolated best supportive care (BSC) in prolonging OS and improving quality of life (QOL) in patients with advanced pancreatic cancer (61). Table II summarizes the most important randomized controlled trials (RCTs) in the first line setting.

In 1997, Burris et al (62) demonstrated GEM to be more effective than 5-FU in palliation of disease-related symptoms, as well as in improving QOL and OS, thereby establishing a new standard of care. In the following years, several GEM-based combination regimens were tested in randomized trials, such as the PA.3 trial (63). When GEM-based combinations were 


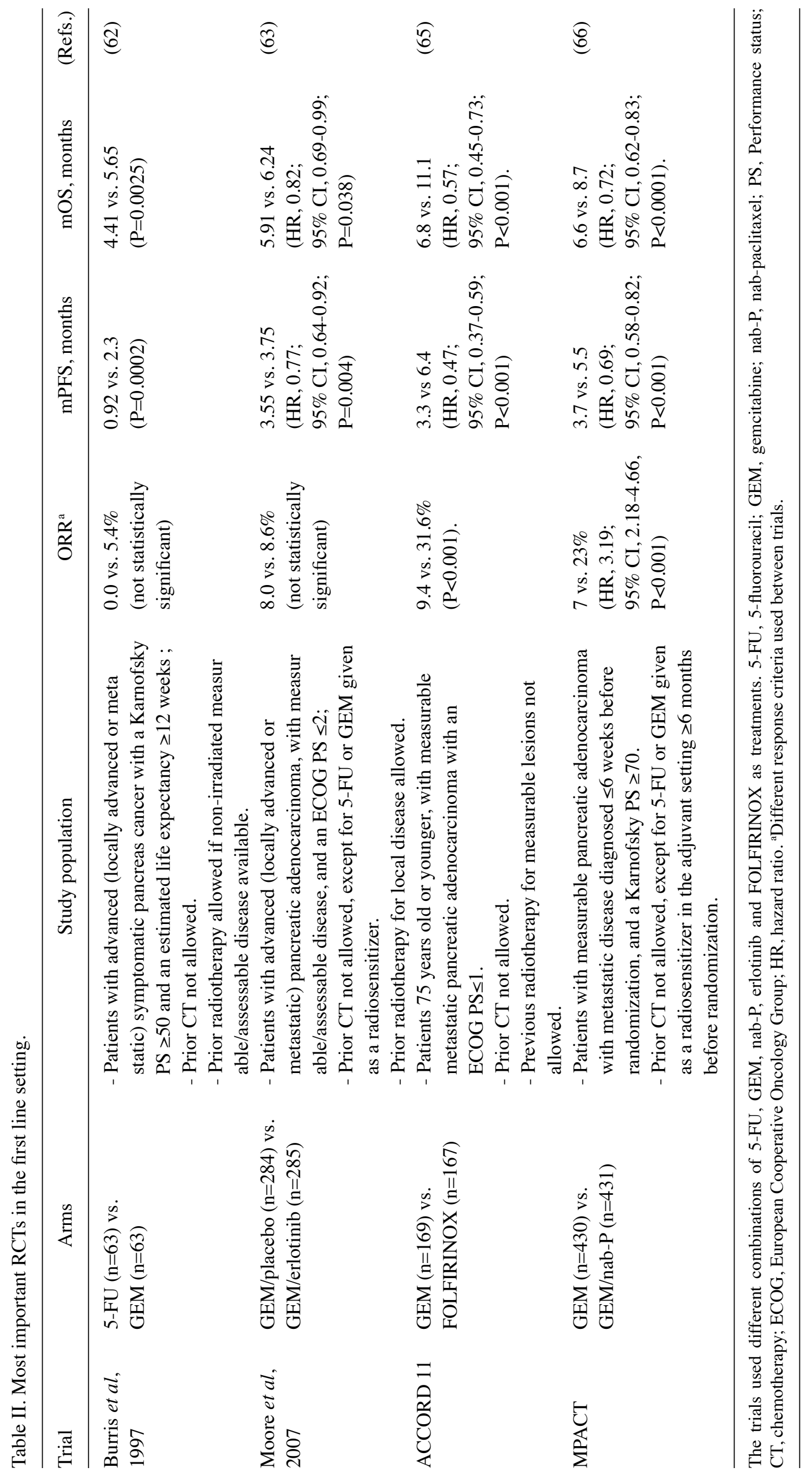


compared with GEM monotherapy in a 2013 meta-analysis, only a small OS improvement was observed in the combination regimens [hazard ratio (HR), 0.93; $\mathrm{P}=0.001$ ], with an increased relative toxicity (64). However, in 2011, the superiority of 6 months of FOLFIRINOX over GEM monotherapy was already established by the phase III ACCORD 11 trial (65). FOLFIRINOX increased overall response rate (ORR), PFS and OS, and despite the greater toxicity, at 6 months significantly fewer patients in the FOLFIRINOX group had a definitive QOL degradation, proving the classic FOLFIRINOX regimen as an option for the treatment of patients with good PS (65).

In 2013, the MPACT trial showed the combination of GEM/nab-P superior to GEM monotherapy with regards to the median OS, median PFS and ORR (66). However, the rates of neuropathy and myelosuppression were also increased.

At present, to the best of our knowledge, there are no prospective, randomized trials, directly comparing GEM/nab-P to FOLFIRINOX. The available evidence comes from retrospective studies and systematic reviews, suggesting there is no major difference in clinical outcomes apart from the toxicity profiles (67).

The GEST trial, a phase III study conducted in Japan and Taiwan, showed the non-inferiority of S-1 compared to GEM in terms of OS (8.8 vs. 9.7 months; HR, 0.96; 97,5\% CI, $0.78-1,18 ; \mathrm{P}<0.001$ for non-inferiority), with good tolerability. In the same study, the combination of GEM and S-1 (GEM/S-1) was not superior to GEM monotherapy (68). More recently, the combination of nab-P with S-1 (nab-P/S-1) was compared to nab-P/GEM in a single-center, Chinese phase II trial, showing comparable efficacy in ORR, PFS and OS, with an improved safety profile (69). Furthermore, to the best of our knowledge, in the Asian population, there are currently no prospective trials comparing GEM/nab-P or nab-P/S-1 to FOLFIRINOX. Therefore, in non-mutation carriers with metastatic pancreatic cancer who are unable or unwilling to participate in a clinical trial, the choice of first line regimen in Europe and United States is usually made between GEM monotherapy, FOLFIRINOX and GEM/nab-P (59,70,71). Most guidelines suggest FOLFIRINOX or GEM/nab-P for PS 0-1 patients with a favorable comorbidity profile, and a serum total bilirubin level $<1.5$ times the upper limit of normal (ULN). The choice between the two regimens is largely based on physician and patient preferences and toxicity profiles, with gastrointestinal, hematological toxicities and fatigue being more common with FOLFIRINOX and alopecia, and neuropathy more evident with GEM/nab-P. For patients with serum bilirubin $>1.5$ times ULN (without a treatable obstruction), FOLFOX-6 may be considered (72). In the Asian population, S-1 combinations can also be an option.

After choosing the regimen, the second question is the duration at which the patient is deriving a clinical benefit. This is especially important considering most protocols can cause cumulative sensory peripheral neuropathy and risk of hypersensitivity reactions. To the best of our knowledge, there are currently no randomized phase III trials comparing the maintenance of the original regimen until disease progression or unacceptable toxicity vs. original regimen for 4 or 6 months followed by 'CT holidays' vs. original regimen for 4 or 6 months and then deescalating to a maintenance regimen ('stop-and-go' strategy).
The phase II PRODIGE 35-PANOPTIMOX study compared 6 months of FOLFIRINOX vs. 4 months of FOLFIRINOX followed by 5-FU maintenance treatment and FOLFIRINOX reintroduction at progression vs. alternating GEM and FOLFIRI-3 every 2 months. In a preliminary report presented at the 2018 annual ASCO meeting, 6-month PFS rates were 47,44 and $34 \%$ for the FOLFIRINOX, maintenance and alternating arms, respectively. The median OS was 10.1, 11.2 and 7.3 months, respectively. Unexpectedly, the rates of severe neurotoxicity were higher in the maintenance therapy arm (19.8 vs. $10.2 \%$ of patients), although it occurred later, possibly due to a higher cumulative oxaliplatin dose in this group (73).

Another phase II trial enrolled 32 patients to four cycles of FOLFOX-6, followed by three cycles of GEM and, in the event of clinical benefit, followed by a maintenance treatment based on the investigator's discretion. The median time to progression and OS were 4 and 10 months, respectively, with no evident efficacy or safety warning signs when compared with the literature (72).

While phase III trials addressing this topic are urgently required, and the available phase II trial evidence offers novel options for maintenance, clinical decisions should be individualized.

Elderly andfrailpatients. Despite contributing to the majority of cases of pancreatic cancer, elderly patients ( $\geq 65$ years old) (74) are repeatedly under-represented in phase III RCTs $(75,76)$. The scarcity of applicable results, the specificities of this subgroup, including pharmacokinetic and pharmacodynamic changes, and the irregular access to comprehensive geriatric assessment, make metastatic pancreatic cancer treatment even more challenging (76,77). Retrospective studies have shown systemic therapy to be associated with longer OS in elderly patients, with a median OS ranging from 8 to 12 months in this subgroup, without compromising QOL (78-80). The available evidence suggests that old age should not preclude patients with good PS, adequate comorbidity profiles and social support from benefiting from protocols such as FOLFIRINOX, mFOLFIRINOX, GEM/nab-P or GEM/CAP (78,81-84).

For frail patients, with $\mathrm{PS} \geq 2$ or a comorbidity profile that precludes intensive therapy, GEM monotherapy is suggested. Where available, S-1 monotherapy is often considered an alternative for frail patients, who prefer the convenience of an oral regimen $(71,72,85,86)$.

In selected patients with $\mathrm{PS} \geq 2$, especially when the disability is due to heavy tumor burden, GEM/nab-P, GEM/CAP or GEM/S-1 (where available) can be considered due to its higher ORR $(68,87,88)$. Patients with a PS $\geq 3$ or poorly controlled comorbid conditions are not included in clinical trials, and BSC and QOL should always be emphasized.

BRCA or PALB2 mutation carriers. In total, 4-7\% of patients with pancreatic cancer have a germline $B R C A$ mutation and up to $1.3 \%$ have a germline $P A L B 2$ mutation. BRCA1, BRCA2 and $P A L B 2$ genes are critical to double-strand DNA repair $(88,89)$. Hence, pathogenic mutations in these genes increase the risk of developing pancreatic cancer (among others), and also render these cancer types more sensitive to DNA damaging agents, such as platinum agents, and to drugs targeting the 
DNA damage response pathway, including poly adenosine diphosphate ribose polymerase (PARP) inhibitors $(90,91)$. Therefore, the ASCO expert panel recommends discussing germline genetic testing for patients with pancreatic cancer, even when the family history is unremarkable (92). Recently, the National Comprehensive Cancer Network (NCCN) guidelines suggest germline testing for any patient with confirmed pancreatic cancer, using comprehensive genes panels for hereditary cancer syndromes (93). Nowadays, the use of this will also depend on the institution, patient characteristics and access to PARP inhibitors.

In the phase III POLO trial, 154 patients with germline BRCA-mutated metastatic PDAC who had not progressed during $\geq 16$ weeks of first-line platinum-based therapy were randomly assigned to maintenance olaparib or placebo (94). The ORR was $23 \%$ in the olaparib group (OR, 2.3; 95\% CI, 0.89-6.76), with a median duration of response of 24.9 months (CI could not be calculated). Among the long-term survivors in the olaparib group $(n=34), 14.7 \%(n=5)$ achieved a complete response, as determined by investigator assessment. No safety red flags or clinically meaningful deterioration in health-related QOL emerged (95). The median PFS was significantly longer in the olaparib group (7.4 vs. 3.8 months; $\mathrm{HR}, 0.53$; $\mathrm{P}=0.004$ ) (96). At 3 years from randomization, $21.5 \%$ of patients in the olaparib arm remained free of subsequent cancer therapy vs. $3.6 \%$ in the placebo arm (HR, 0.44 ; nominal $\mathrm{P}<0.0001)(96)$. The median time from randomization to second disease progression or death showed a benefiting trend in favor of olaparib but was not $\alpha$ protected (median 16.9 and 9.3 months; HR, 0.66, 0.43-1.03; $\mathrm{P}=0.0613$ ). After a median follow up of 23.9 and 31.3 months, OS was similar between groups (median 19.0 and 19.2 months; HR, 0.83; 95\% CI, 0.56-1.22; $\mathrm{P}=0.3487$ ). However, the study was not statistically powered to evidence survival differences (96).

On the other hand, a phase II trial of GEM and cisplatin with or without veliparib in germline $B R C A / P A L B 2$-mutated cases with stage III or IV pancreatic cancer, was not statistically significant with regards the primary end-point, as the ORR was 74.1 (with cisplatin/GEM and veliparib) vs. $65.2 \%$ (cisplatin/GEM) $(\mathrm{P}=0.55)(97)$. These results reinforced the use of a combination containing a platinum-based therapy in these patients. Nevertheless, the unprecedented high ORR in the GEM plus cisplatin arm reinforced this regimen as a highly effective CT option in this setting.

Despite the absence of trials randomizing patients with germline $B R C A$ or $P A L B 2$ mutation between initial platinumvs. non-platinum-containing $C \mathrm{~T}$, the high ORR and prolonged survivals support the recommendation of a platinum-based $\mathrm{CT}$ regimen in the first line treatment of metastatic pancreatic cancer arising in the setting of a known germline $B R C A 1$ or PALB2 mutation (98). Moreover, maintenance with olaparib, based on the POLO trial, only applies to patients with clinical benefit on initial platinum-based CT. Depending on the PS, comorbidities, serum bilirubin and preferences, FOLFIRINOX, mFOLFIRINOX, FOLFOX or GEM plus cisplatin can be considered. In mutation carriers deriving clinical benefit from a first line platinum-based CT, whether to maintain the initial regimen, to deescalate to a maintenance $\mathrm{CT}$ regimen without platinum, to stop all CT after 6 months or to switch to olaparib remain unanswered questions. It is a matter of debate whether, in the absence of an OS benefit and in the presence of some design flaws (absence of an active control arm), the POLO trial can change the standard of care (99). Certainly, it is a new option in a field where targeted and maintenance therapy are urgently required.

In most cases, metastatic pancreatic cancer is diagnosed in a patient with unknown mutational status. Given that molecular analysis usually takes $\geq 4$ weeks to complete, the low probability of mutation and the aggressiveness of pancreatic cancer, it is not currently recommended to wait for the genetic results to begin $\mathrm{CT}$. Instead, treatment with a platinum-based regimen can be started, although it is not wrong to begin with GEM/nab-P. If the patient starts with GEM/nab-P and then is found to have a germline $B R C A$ or $P A L B 2$ mutation, a platinum-containing regimen and PARP inhibitors may be considered in subsequent lines $(59,71,86)$.

FOLFIRINOX and GEM/nab-P are the two most consensual regiments in the first-line therapy for patients with ECOG PS 0-1, and the choice must be based on the toxicity profile of each regimen and the physician and patient preferences. The center experience in managing toxicities is also crucial in this context. In frail and elderly patients, the recommended regimen is GEM monotherapy, although S-1 can be preferred, if available, due to patient convenience. According to the POLO trial, in the context of $B R C A$-mutated metastatic PDAC, olaparib is a valid option as a maintenance therapy for patients whose PDAC did not progress during $\geq 16$ weeks of first-line treatment with a platinum-based protocol (86).

Second line setting. Upon progression, reevaluating the patient's PS, comorbidities, residual toxicities and expectations is mandatory. Second line therapy in advanced PDAC is not consensual and different studies have been conducted with the aim of providing clinicians with evidence regarding the most effective and secure second line CT option.

A comprehensive analysis of 44 clinical trials comparing therapeutic approaches in this setting concluded that data regarding second line $\mathrm{CT}$ in PDAC are limited, and that additional studies are required (100). Despite this, second line CT is being increasingly considered in patients with PS $<2$. For PS $\leq 1$ cases, the choice depends on the previous line of CT. For patients with PS $\geq 2$, in some cases, second line can be considered, although controversial, and in several cases, it will be a monotherapy. Once again, a PS $\geq 3$ favors BSC $(46,70,86,101)$.

After progression on GEM. Different studies have evaluated the best second line therapeutic options for patients with advanced PDAC upon progression on a GEM-based first line (100). A meta-analysis published in 2017 included five studies and 895 patients, and concluded that combinations including oxaliplatin or irinotecan formulations resulted in an improvement in PFS compared with monotherapy. However, only the combination with a fluoropyrimidine conferred an advantage regarding OS, although the evidence was scarce (102).

After progression under GEM-based CT in first line, oxaliplatin, folinic acid and leucovorin (FA) and 5-FU (OFF) vs. FA and 5-FU alone (FF) were tested in a German phase III study including 168 patients. The median OS in the OFF group was significantly increased compared with the FF group 
(5.9 vs. 3.3 months; $P=0.010)(103,104)$. The rates of adverse effects (AEs) were similar between groups. In clinical practice this has become a widely used second line (104).

PANCREOX was a phase III trial that included patients with advanced PDAC previously treated with GEM-based CT who had a PS $<2$. Patients were randomized to receive bi-weekly mFOLFOX6 vs. infusional 5-FU and leucovorin (5-FU/LV) until progression. Unexpectedly, oxaliplatin association conferred no benefit, thereby suggesting $5-\mathrm{FU} / \mathrm{LV}$ as a reasonable and well tolerated second line (105). For patients with progressive disease on GEM, other oxaliplatin-based regimens are also active, namely combinations with capecitabine (101,106), S-1 (107,108), GEM (109), irinotecan or docetaxel (110).

Nanoliposomal irinotecan plus 5-FU/LV was compared with 5-FU/LV or nanoliposomal irinotecan alone in the NAPOLI-1 trial, which was a phase III study that included 417 patients with metastatic PDAC previously treated with GEM-based therapy. The median OS was, respectively, 6.2 vs. 4.2 (HR, $0.75 ; 95 \% \mathrm{CI}, 0.57-0.99$ ) vs. 4.9 months, favoring the group of nanoliposomal irinotecan plus 5-FU/LV against the monotherapy arms. PFS, ORR and disease control rate (DCR) also favored the nanoliposomal irinotecan plus 5 -FU/LV arm. The safety profile was considered manageable, making this scheme an option in patients treated with GEM-based CT in first line, according to the European Society for Medical Oncology (ESMO) and ASCO guidelines $(70,86)$.

After progression on fluoropyrimidine. After a first line fluoropyrimidine-based CT (mostly FOLFIRINOX), a second line GEM-based regimen is usually advised. Moreover, the enrolment on clinical trials if possible is a favorable choice. GEM/nab-P has been studied in a clinical trial after FOLFIRINOX failure, which included 75 patients with advanced pancreatic cancer (111). Patients were treated with GEM/nab-P until disease progression, patient refusal or unacceptable toxicity, for a median of four cycles. A DCR of $58 \%$, an ORR of $17.5 \%$, a median OS of 8.8 months (95\% CI, 6.2-9.7) and a median PFS of 5.1 months (95\% CI, 3.2-6.2) were observed. Although grade 3-4 AEs were reported in $40 \%$ of the patients, the authors considered the toxicity profile manageable, concluding that GEM/nab-P appeared to be effective as second line CT in patients with metastatic PDAC after FOLFIRINOX/fluoropyrimidine-based first line (111).

The ESMO and ASCO guidelines both include GEM-based CT (GEM/nab-P or GEM/CAP) as second line options in patients with PS $<2$. For patients with $\mathrm{PS} \geq 2$, monotherapy with GEM and/or BSC should be considered. For the majority of patients with PS $\geq 3$, BSC is the best option $(59,70)$.

MMR-deficient/high microsatellite instability (MSI). MMR defects can lead to frequent somatic mutations and high MSI and, consequently, to tumors that may be susceptible to immune checkpoint blockade $(112,113)$. The efficacy of pembrolizumab, an anti-programmed cell death protein-1 (PD-1) reagent, was tested in MSI/MMR-deficient non-colorectal cancer cases in the KEYNOTE-158 trial, a phase II study that included 233 patients with different types of cancers, with PDAC being one of the most frequent types, and in tumors that showed failure with prior therapy and had received pembrolizumab. The ORR was $18.2 \%$ (95\% CI, 20.3-66.5) and median PFS was 9.2 months. Taken together, these results demonstrated a clinical benefit of pembrolizumab in patients with unresectable metastatic PDAC with high microsatellite instability/deficiency in DNA MMR (114).

Recently, the COMBAT trial, a single-arm phase IIa study that enrolled 37 patients, assessed the safety, efficacy and immunobiological effects of C-X-C motif chemokine receptor 4 and PD-1 blockade, with BL-8040 and pembrolizumab, respectively, in patients with metastatic PDAC refractory to one or more previous lines of CT (115). The DCR was 34.5\% in the evaluable population ( $31 \%$ with stable disease and $3.4 \%$ with partial response). The median OS was 3.3 months in the intention to treat population and 7.5 months in patients receiving the drugs as second line therapy (115). These data suggested that BL-8040 and pembrolizumab may increase the benefit of CT, but further randomized trials are required.

A rare subtype of PDAC (0.34-0.5\%) has neutrophic-TRK (NTRK) gene fusions and may benefit from larotrectinib or entrectinib therapy (116-119). This issue will be addressed elsewhere in this article.

Collectively the second line options depend on various factors, including the first line therapy and patient clinical characteristics, such as PS, co-morbidities, residual toxicities, and patient expectations. For second line therapy-eligible patients, after progression on gemcitabine, both the combination of oxaliplatin to 5-FU/LV and nanoliposomal irinotecan plus 5-FU/LV are options. On the other hand, GEM-based CT after a fluoropyrimidine-based CT (usually FOLFIRINOX) is recommended. In patients with MMR-deficient/MSI-high tumors, immunotherapy can be an option as there are some data regarding pembrolizumab, irrespectively of first-line treatment. Integrating this information, Fig. 3 represents a proposal for PDAC treatment in the metastatic setting (120).

\section{New therapeutic targets and biomarkers}

The lack of therapeutic options that significantly improve the prognosis of patients not eligible for surgical resection, and the absence of biomarkers able to detect early lesions, are reflected in the poor prognosis of this disease. Thus, new therapeutic strategies are required to control and eradicate PDAC. Since its cells are genetically unstable, and the number of somatic mutations appears to be higher in the genomes of cancer types with MMR deficiency, the efforts to apply immunotherapy to PDAC treatment are a major focus of current research.

Recently, the genome of 385 patients with PDAC was studied, and the main mutational signatures were defects in DNA repair, with MMR deficiency identified in $1 \%$ of the tumors harboring different mechanism of mutL homolog 1 and mutS homolog 2 somatic inactivation (121). Despite these recent data, there remain numerous important research areas to explore and obstacles to overcome in PDAC, such as who to treat and how therapy should be delivered (122).

Beyond immune checkpoint inhibitors there are three other main classes of immunotherapy being evaluated, including: Vaccines, adaptive $\mathrm{T}$ cell therapy and monoclonal antibodies. Currently, neither vaccines or monoclonal antibodies have 


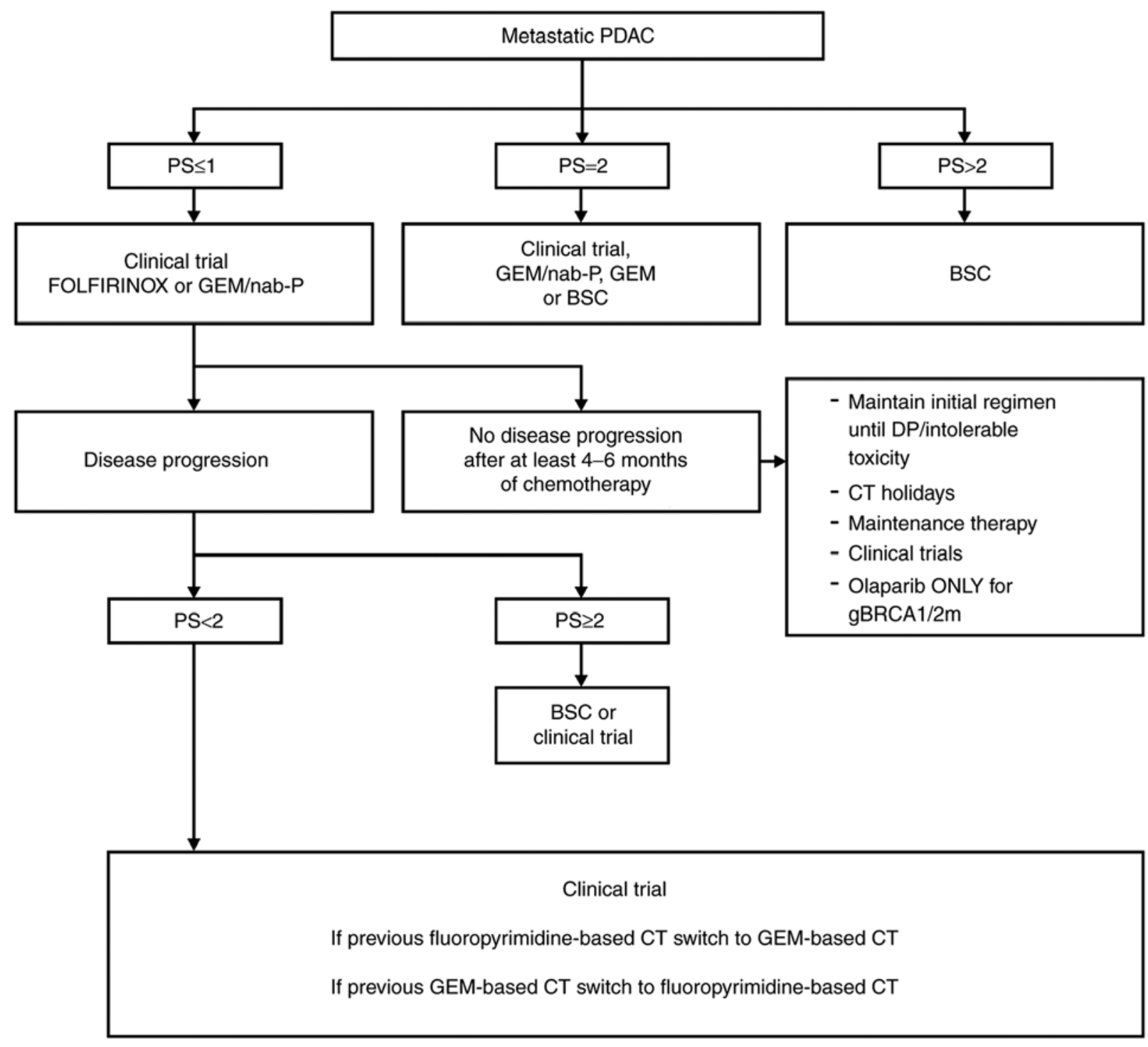

Figure 3. Proposal for PDAC treatment in the metastatic setting. PS, performance status; PDAC, pancreatic ductal adenocarcinoma; BSC, best supportive care; GEM, gemcitabine; nab-P, nab-paclitaxel; CT, chemotherapy; DP, disease progression.

shown significant benefit. Regarding adaptive T cell therapy, there are very few identified potential antigens and its cost and time-consuming process hamper its progress in PDAC, which has been very slow (122).

Various research projects, using different laboratory models, have been performed in the past years to overcome PDAC. Global genomic analysis could provide new insights on its pathogenesis, as most of the mutations found are point mutations that occur in $67-100 \%$ of the tumors and affect 12 cellular core signaling pathways, which could explain the major features of pancreatic tumorigenesis $(122,123)$.

It is known that epidermal growth factor receptor (EGFR) is expressed during pancreatic injury and in the pre-neoplastic lesions. The KRAS oncogenes are dependent on EGFR signaling, and loss of EGFR increases tumor latency and survival. In addition, tumor explants lacking p53 and EGFR are sensitive to the combined inhibition of PI3K and STAT3 (124-127). Based on these findings, successful strategies for the treatment of advanced human PDAC may require the inhibition of four signaling cascades driven by KRAS,
EGFR, PI3K and STAT3 (125). A study with engineered exosomes carrying small interfering RNA (siRNA) or short hairpin RNA specific to oncogenic $K R A S^{\mathrm{G} 12 \mathrm{D}}$ (iExosomes) demonstrated that these structures were able to suppress pancreatic cancer growth in multiple mouse models and significantly increase OS (128). Based on these results, a phase I clinical trial is underway to evaluate the best dose and the side effects of mesenchymal stromal cells-derived exosomes with $K R A S^{\mathrm{G} 12 \mathrm{D}}$ siRNA (iExosomes) in treating PDAC cases with $K R A S^{\mathrm{G} 12 \mathrm{D}}$ mutation that has spread (129).

In a previous study in which xenografts of resectable PDAC were implanted in nude mice, the rate of engraftment was $61 \%$, and the authors concluded that SMAD4 inactivation in tumors contributed to the engraftment rate (130). Moreover, engraftment was a factor of poor prognosis, and these tumors had a metastatic gene expression signature. This model could be useful to perform drug screening, biomarkers research and help further understand the biology of PDAC (130). The use of mouse models has already identified Hedgehog signaling as a key biological feature in the metastatic spread (131), 
which was associated with an inefficient drug delivery that could contribute to chemo-resistance, namely to GEM. The co-administration of a Hedgehog signaling inhibitor and GEM increases the intra-tumoral concentration of GEM (132). The ineffective delivery of CT drugs was also restored in murine models through the ablation of the abundant matrix glycosaminoglycan that creates a drug-free sanctuary in PDAC (133). This intrinsic chemo-resistance characteristic is associated with a growth-permissive tumor environment. Reprograming the tumor stroma could enable an increased response to CT, which may be accomplished by adding vitamin $\mathrm{D}$ to the standard therapy (134). Although adding calcipotriol to cell lines and murine models reduces inflammatory markers and fibrosis, which can favor drug activity (134), data from the largest combination of European cohort studies did not show a difference in PDAC risk associated with the pre-diagnostic concentrations of vitamin D (135). This may be justified by the simultaneous reduction in $\mathrm{T}$ cell effector functions, which could compromise the patients' tumor immune surveillance. Moreover, calcipotriol dual effects can play and important role in PDAC (136).

To further understand the biology of metastatic PDAC, large scale multi-omics approaches have been used. A more mesenchymal transcriptomic subtype has been associated with metastases and consequently with poor prognosis $(127,137)$. Nevertheless, it appears not to be sufficient since cancer cells require a pre-metastatic niche to survive in a distant organ (137). One of the players in the construction of the immunosuppressive microenvironment in locally advanced PDAC is the chemokine axis $\mathrm{C}-\mathrm{C}$ motif chemokine ligand $2 / \mathrm{C}-\mathrm{C}$ motif chemokine receptor (CCR) (138). In pre-clinical models, it has been reported that the inhibition of this axis leads to the restoration of antitumor immunity (138). As aforementioned, based on these data, a phase Ib clinical trial was performed to test the safety and tolerability of an CCR 2 inhibitor in combination with FOLFIRINOX. The results showed that the combination is safe and tolerable (127).

Another important family of receptors that are associated with cancer include the neutrophic-TRK (NTRK) genes (139). Fusions involving these genes appear to be oncogenic drivers (139). These fusions are observed in $0.31 \%$ of adult tumors, although other alterations such as mutations, amplifications and mRNA overexpression were found to occur in $14.2 \%$ of the 13,467 analyzed samples (primary cancer and matched sampled) from The Cancer Genome Atlas (116). Entrectinib, a selective tyrosine kinase inhibitor of the C-ros oncogene 1 (ROS1), TRK and anaplastic lymphoma kinase (ALK), has shown clinical activity in patients with different locally advanced or metastatic solid tumors (140). In total, 3 cases of PDAC with gene fusions ( 2 with translocated promotor region-NTRK and 1 with scarecrow-like protein 4-ROS1) were treated with entrectinib and showed clinical improvement and CA 19.9 normalization (139). These data revealed the importance of earlier molecular testing contributing to a personalized therapy in the context of PDAC and allowing for improved survival and ORR. It has also been shown that gene fusion of $A L K$ leads to constitutive activation of oncogenic pathways (140). Furthermore, inhibition of the ALK signaling pathway by using crizotinib in pancreatic cancer cell lines resulted in the inhibition of cell proliferation/angiogenesis and in apoptosis induction (141). Thus, this drug could potentially be a new therapeutic agent for PDAC.

The early detection of PDAC without the use of invasive methods is challenging (142). Currently, the only used serum marker for PDAC is CA $19.9(143,144)$, and its elevation correlates with advanced PDAC and poor prognosis $(145,146)$. However, high CA 19.9 levels can also be caused by numerous other conditions, including various benign diseases (147) or other cancer types (145). Therefore, CA 19.9 is not recommended as a screening marker for PDAC (146). Ongoing studies are focusing on directly exploring if CA 19.9 in combination with other markers could yield improved sensitivity and specificity.

Recently the potential for using liquid biopsy has been investigated, more specifically through the analysis of circulating tumor cells, circulating tumor DNA and exosomes. These last structures are extracellular vesicles released by all cells, including cancer cells, which carry genetic and molecular material providing a view of the content of the cells of origin (148). Exosomes are therefore a promising biological material from patients with cancer that require further validation and technological improvement allowing for their use in early detection and disease monitoring $(149,150)$. Besides these reported studies, there are other currently ongoing phase III trials in PDAC using new therapeutic targets and approaches, which are summarized in Table III.

\section{Conclusion}

Nowadays, PDAC is a key issue in the oncology field since its incidence is growing as much as its mortality. Among the different available therapeutic options for the treatment of advanced PDAC, results are modest, probably due to the complexity of the disease, and the prognostic remains poor. Further economic investment in basic research and integration of data provided by distinct platforms (genomics, transcriptomics, proteomics, epigenomics and metabolomics) offers a plethora of opportunities to identify causal relationships occurring between molecular alterations and phenotypes. The perspective of multi-omics as a valuable tool to subtype tumors and provide prognosis is exciting but is far from becoming a reality in medical routine. Notwithstanding, the use of these high throughput technologies in the pursuit of novel biomarkers and identification of therapeutic opportunities is highly significant. This can provide a framework in which multi-omics data integration can be translated in valuable biomarkers with clinical utility. Furthermore, understanding the balance and influence of the stroma in tumor evolution could represent a significant step forward in therapeutic efficiency. The development of guidelines for early detection in special risk groups (genetic risk groups, individuals with relatives diagnosed with pancreatic cancer, smokers, alcohol consumers, type 2 diabetics, patients with chronic pancreatitis and obese individuals), as well as the implementation of national public health plans, thereby creating awareness both in the medical community and in the public, should also be priorities for investment. The success of these strategies has been already witnessed with other tumors and are imperative in pancreatic cancer. 
Table III. Ongoing phase III trials in pancreatic ductal adenocarcinoma.

$\begin{array}{lll}\text { Study Main outcome } & \text { Matcin }\end{array}$

NAPOLI 3 (NCT04083235)

PANOVA-3 (NCT03377491)

(NCT03126435)

(NCT01954992)

Trybeca-1 (NCT03665441)

(NCT03504423)
Condition: Metastatic Adenocarcinoma of the Pancreas

Setting: Frontline

n=750 (Estimated study completion December 31, 2023)

Arms: Irinotecan liposome injection/Oxaliplatin/5-FU/LV vs. nab-P/GEM

Allocation: Randomized

Masking: None (Open Label)

Follow-up: Until progression or unacceptable toxicity

Primary outcome measures: OS

Condition: Locally advanced Pancreas Adenocarcinoma

Setting: Frontline

$\mathrm{n}=556$ (Estimated study completion September 2023)

Arms: NovoTTF-100L(P) vs. GEM/nab-P

Allocation: Randomized

Masking: None (Open Label)

Follow-up: 4 years

Primary outcome measures: OS

Condition: Locally/advanced and/or Metastatic Pancreas Adenocarcinoma who failed on first line FOLFIRINOX

Setting: 2nd line

$\mathrm{n}=218$ (Estimated study completion June 2022)

Arms: EndoTAG-1/GEM vs. GEM

Allocation: Randomized

Masking: None (Open Label)

Follow-up: Until progressive disease, unacceptable toxicity or withdrawal of consent occurs

Primary outcome measures: OS

Condition: Metastatic Pancreatic Adenocarcinoma previously treated with GEM

Setting: 2nd line

$\mathrm{n}=480$ (Estimated study completion June 2021)

Arms: Glufosfamide vs. 5-FU

Allocation: Randomized

Masking: None (Open Label)

Follow-up: 3-6 months

Primary outcome measures: OS

Condition: Pancreas Adenocarcinoma who have failed only one prior line of systemic anti-cancer therapy for advanced pancreatic cancer

Setting: 2nd line

n=500 (Estimated study completion April 2021)

Arms: Eryaspase/nab-P/GEM vs. Irinotecan/LV/5-FU vs. FOLFIRI/LV/5-FU vs.

GEM/nab-P OR Irinotecan/5-FU/LV

Allocation: Randomized

Masking: None (Open Label)

Follow-up: 1 year after last patient randomized

Primary outcome measures: OS

Condition: Metastatic Pancreas Adenocarcinoma

Setting: 2nd line

$\mathrm{n}=500$ (Estimated study completion March 2022)

Arms: CPI-613/mFOLFIRINOX vs. FOLFIRINOX

Allocation: Randomized

Masking: None (Open Label)

Follow-up: At least 6 months

Primary outcome measures: ORR 
Table III. Continued.

\begin{tabular}{|c|c|}
\hline Study & Main outcome \\
\hline HEAT (NCT01077427) & $\begin{array}{l}\text { Condition: Resected Pancreatic Adenocarcinoma } \\
\text { Setting: Frontline } \\
\text { n=336 (Estimated study completion March 2021) } \\
\text { Arms: GEM/CAP vs. GEM/Cisplatin with regional hyperthermia } \\
\text { Allocation: Randomized } \\
\text { Masking: None (Open Label) } \\
\text { Follow-up: From date of randomization until the date of first documented progression } \\
\text { or date of death from any cause, whichever came first, assessed up to } 60 \text { months } \\
\text { Primary outcome measures:DFS }\end{array}$ \\
\hline (NCT04229004) & $\begin{array}{l}\text { Condition: Metastatic Pancreatic Cancer } \\
\text { Setting: } 1 \text { st or } 2 \text { nd line } \\
\text { n=825 (Estimated study completion February 20, 2024) } \\
\text { Arms: GEM/nab-P vs. SM-88/methoxsalen/phenytoin/sirolimus vs. mFOLFIRINOX } \\
\text { Allocation: Randomized } \\
\text { Masking: None (Open Label) } \\
\text { Follow-up: Up to } 2 \text { years } \\
\text { Primary outcome measures: OS }\end{array}$ \\
\hline DIRECT (NCT03899636) & $\begin{array}{l}\text { Condition: Stage III Pancreatic Cancer } \\
\text { Setting: 2nd line } \\
\text { n=528 (Estimated study completion December 2023) } \\
\text { Arms: mFOLFIRINOX/IRE using NanoKnife System vs. } \\
\text { mFOLFIRINOX } \\
\text { Allocation: Randomized } \\
\text { Masking: None (Open Label) } \\
\text { Follow-up: At least } 24 \text { months } \\
\text { Primary outcome measures:OS }\end{array}$ \\
\hline RELIANT (NCT04329949) & $\begin{array}{l}\text { Condition: Metastatic Pancreatic Ductal Adenocarcinoma } \\
\text { Setting: 3rd or subsequent lines } \\
\mathrm{n}=80 \text { (Estimated study completion January 2022) } \\
\text { Arms: Relacorilant/nab-P } \\
\text { Allocation: N/A } \\
\text { Masking: None (Open Label) } \\
\text { Follow-up: Enrolment through } 24 \text { months } \\
\text { Primary outcome measures: ORR per BICR }\end{array}$ \\
\hline
\end{tabular}

OS, overall survival; ORR, objective response rate; DFS, disease-free survival; BICR, blinded independent central review; 5-FU, 5-fluorouracil; GEM, gemcitabine; nab-P, nab-paclitaxel; LV, leucovirin,

\section{Acknowledgements}

Not applicable.

\section{Funding}

Editorial support, in the form of medical writing and editing assistance, in the development of this manuscript was provided by $\mathrm{x} 2$-Science Solutions, and was unconditionally funded by AstraZeneca plc. AstraZeneca plc had no role in the conduct of the research, in study design, in the collection, analysis and interpretation of data, in the writing of the report or in the decision to submit the article for publication.

\section{Availability of data and materials}

Not applicable.

\section{Authors' contributions}

Study conception and design was developed by HM. The manuscript draft was written by all authors. A critical revision of the manuscript was performed by AGB, CFP, MM, NC, OS, SAM and HM. All authors contributed for the acquisition, analysis, and interpretation of data for the work, read and approved the final version of the manuscript and agreed to be accountable for all aspects of the work, ensuring that questions 
related to the accuracy or integrity of any part of the work are appropriately investigated and resolved. Data sharing is not applicable.

\section{Ethics approval and consent to participate}

Not applicable.

\section{Patient consent for publication}

Not applicable.

\section{Competing interests}

Author AGB declares to have received fees from Amgen, Inc., AstraZeneca plc, Bristol Myers Squibb, Incyte Corp, Eli Lilly and Company, Merck Serono, MSD, Novartis International AG, Laboratories Pierre Fabre, Roche Diagnostics and Laboratories Servier, either by participation in advisory boards, as invited speaker or in the form of research projects grants. Author CFP declares to have received fees from AstraZeneca plc, Roche Diagnostics, Pfizer, Inc., Daiichi-Sankyo Co., Ltd., Leo Farma A/S, Novartis International AG and Grünenthal. Author MM declares to have received fees from AstraZeneca plc, Roche Diagnostics, Merck KGaA, MSD, Laboratories Servier, Bayer and Angelini Pharma from participation in advisory boards. Author NC declares to have received fees from Laboratories Servier from participation in advisory boards. Authors MJB and OS declare to have received fees from AstraZeneca plc. Author HM declares to have received fees from AstraZeneca plc, Roche Diagnostics, Pfizer, Inc., Laboratories Pierre Fabre, Incyte Corp., BMS, Novartis International AG, Amgen, Inc., Laboratories Servier, Merck Serono, and Grünenthal either by participation in advisory boards or as invited speaker.

Author SAM declares to hold patents in the area of exosomes biology and that these are licensed to Codiak Biosciences, Inc. Patents: i) Title: mirna biogenesis in exosomes for diagnosis and therapy; Patent no. 20200255831; Filed: March 23, 2020; Publication date: August 13, 2020; Inventors: Raghu Kalluri, Sónia Melo; United States of America, US. ii) Title: miRNA biogenesis in exosomes for diagnosis and therapy; Patent no. 20160024503; Filed: March 14, 2014; Publication date: January 28, 2016; Inventors: Raghu Kalluri, Sónia Melo; United States of America, US. iii) Title: use of exosomes for the treatment of disease; Patent no. 20180177727; Filed: June 10, 2016; Publication date: June 28, 2018; Inventors: Raghu Kalluri, Sónia Melo; United States of America, US. iv) Title: use of exosomes for the treatment of disease; Patent no. 20190117570; Filed: November 28, 2018; Publication date: April 25, 2019; Inventors: Raghu Kalluri, Sónia Melo; United States of America, US. v) Title: Use of exosomes for the treatment of disease; Patent no. 10959952; Filed: November 28, 2018; Date of Patent: March 30, 2021; Inventors: Raghu Kalluri, Sónia Melo; United States of America, US. vi) Title: Analysis of genomic DNA, RNA, and proteins in exosomes for diagnosis and theranosis; Patent no. 20200200755; Filed: March 4, 2020; Publication date: June 25, 2020; Inventors: Raghu Kalluri, Sónia Melo; United States of America, US. vii) Analysis of genomic DNA, RNA, and proteins in exosomes for diagnosis and theranosis; Patent no. 20170059572; Filed: December 4, 2014; Publication date: March 2, 2017; Inventors: Raghu Kalluri, Sónia Melo; United States of America, US. viii) Analysis of genomic DNA, RNA, and proteins in exosomes for diagnosis and theranosis; Patent no. 20180045728; Filed: November 1, 2017; Publication date: February 15, 2018; Inventors: Raghu Kalluri, Sónia Melo; United States of America, US. ix) Analysis of genomic DNA, RNA, and proteins in exosomes for diagnosis and theranosis; Patent no. 10598665; Filed: November 1, 2017; Date of Patent: March 24, 2020; Inventors: Raghu Kalluri, Sónia Melo; United States of America, US. x) Analysis of genomic DNA, RNA, and proteins in exosomes for diagnosis and theranosis; Patent no. 9921223; Filed: December 4, 2014; Date of Patent: March 20, 2018; Inventors: Raghu Kalluri, Sónia Melo; United States of America, US.

\section{References}

1. Karim-Kos HE, de Vries E, Soerjomataram I, Lemmens V, Siesling S and Coebergh JW: Recent trends of cancer in Europe: A combined approach of incidence, survival and mortality for 17 cancer sites since the 1990s. Eur J Cancer 44: 1345-1389, 2008.

2. International Agency for Research on Cancer WHO: Pancreas. Source: Globocan 2020. Available from: https://gcoiarcfr/ today/data/factsheets/cancers/13-Pancreas-fact-sheetpdf, 2020.

3. American Cancer Society: Cancer Facts and Figures, 2019.

4. Ferlay J, Steliarova-Foucher E, Lortet-Tieulent J, Rosso S, Coebergh JW, Comber H, Forman D and Bray F: Cancer incidence and mortality patterns in Europe: Estimates for 40 countries in 2012. Eur J Cancer 49: 1374-1403, 2013.

5. Hidalgo M, Cascinu S, Kleeff J, Labianca R, Löhr JM, Neoptolemos J, Real FX, Van Laethem JL and Heinemann V: Addressing the challenges of pancreatic cancer: Future directions for improving outcomes. Pancreatology 15: 8-18, 2015.

6. Ilic M and Ilic I: Epidemiology of pancreatic cancer. World J Gastroenterol 22: 9694-9705, 2016.

7. Carrato A, Falcone A, Ducreux M, Valle JW, Parnaby A, Djazouli K, Alnwick-Allu K, Hutchings A, Palaska C and Parthenaki I: A systematic review of the burden of pancreatic cancer in europe: Real-world impact on survival, quality of life and costs. J Gastrointest Cancer 46: 201-211, 2015.

8. Aune D, Greenwood DC, Chan DS, Vieira R, Vieira AR, Navarro Rosenblatt DA, Cade JE, Burley VJ and Norat T: Body mass index, abdominal fatness and pancreatic cancer risk: A systematic review and non-linear dose-response meta-analysis of prospective studies. Ann Oncol 23: 843-852, 2012.

9. Nöthlings U, Wilkens LR, Murphy SP, Hankin JH, Henderson BE and Kolonel LN: Body mass index and physical activity as risk factors for pancreatic cancer: The multiethnic cohort study. Cancer Causes Control 18: 165-175, 2007.

10. Pratapwar M, Stenzel AE, Joseph JM, Fountzilas C, Etter JL, Mongiovi JM, Cannioto R and Moysich KB: Physical inactivity and pancreatic cancer mortality. J Gastrointest Cancer 51: 1088-1093, 2020.

11. Bosetti C, Lucenteforte E, Silverman DT, Petersen G, Bracci PM, Ji BT, Negri E, Li D, Risch HA, Olson SH, et al: Cigarette smoking and pancreatic cancer: An analysis from the international pancreatic cancer case-control consortium (Panc4). Ann Oncol 23: 1880-1888, 2012.

12. Iodice S, Gandini S, Maisonneuve P and Lowenfels AB: Tobacco and the risk of pancreatic cancer: A review and meta-analysis. Langenbecks Arch Surg 393: 535-545, 2008.

13. Duell EJ, Lucenteforte E, Olson SH, Bracci PM, Li D, Risch HA, Silverman DT, Ji BT, Gallinger S, Holly EA, et al: Pancreatitis and pancreatic cancer risk: A pooled analysis in the international pancreatic cancer case-control consortium (PanC4). Ann Oncol 23: 2964-2970, 2012.

14. Rebours V, Boutron-Ruault MC, Schnee M, Férec C, Maire F, Hammel P, Ruszniewski P and Lévy P: Risk of pancreatic adenocarcinoma in patients with hereditary pancreatitis: A national exhaustive series. Am J Gastroenterol 103: 111-119, 2008.

15. Ben Q, Xu M, Ning X, Liu J, Hong S, Huang W, Zhang H and Li Z: Diabetes mellitus and risk of pancreatic cancer: A meta-analysis of cohort studies. Eur J Cancer 47: 1928-1937, 2011. 
16. McWilliams RR, Maisonneuve P, Bamlet WR, Petersen GM, Li D, Risch HA, Yu H, Fontham ET, Luckett B, Bosetti C, et al: Risk factors for early-onset and very-early-onset pancreatic adenocarcinoma: A pancreatic cancer case-control consortium (PanC4) analysis. Pancreas 45: 311-316, 2016.

17. Pancreatic Cancer Europe: Pancreatic Cancer Inequality Report https://wwwpancreaticcancereuropeeu/campaign/the-pancreaticcancer-europe-inequality-report/, 2018.

18. Klein AP, Lindström S, Mendelsohn JB, Steplowski E, Arslan AA, Bueno-de-Mesquita HB, Fuchs CS, Gallinger S, Gross M, Helzlsouer K, et al: An absolute risk model to identify individuals at elevated risk for pancreatic cancer in the general population. PLoS One 8: e72311, 2013.

19. Whitcomb DC: Genetics of alcoholic and nonalcoholic pancreatitis. Curr Opin Gastroenterol 28: 501-506, 2012.

20. Whitcomb DC, Gorry MC, Preston RA, Furey W, Sossenheimer MJ, Ulrich CD, Martin SP, Gates LK Jr, Amann ST, Toskes PP, et al: Hereditary pancreatitis is caused by a mutation in the cationic trypsinogen gene. Nat Genet 14: $141-145,1996$

21. Witt H, Luck W, Hennies HC, Classen M, Kage A, Lass U, Landt $\mathrm{O}$ and Becker M: Mutations in the gene encoding the serine protease inhibitor, Kazal type 1 are associated with chronic pancreatitis. Nat Genet 25: 213-216, 2000.

22. Wolfgang CL, Herman JM, Laheru DA, Klein AP, Erdek MA, Fishman EK and Hruban RH: Recent progress in pancreatic cancer. CA Cancer J Clin 63: 318-348, 2013.

23. Giardiello FM, Brensinger JD, Tersmette AC, Goodman SN, Petersen GM, Booker SV, Cruz-Correa M and Offerhaus JA Very high risk of cancer in familial Peutz-Jeghers syndrome. Gastroenterology 119: 1447-1453, 2000.

24. Iqbal J, Ragone A, Lubinski J, Lynch HT, Moller P, Ghadirian P, Foulkes WD, Armel S, Eisen A, Neuhausen SL, et al: The incidence of pancreatic cancer in BRCA1 and BRCA2 mutation carriers. Br J Cancer 107: 2005-2009, 2012.

25. Kastrinos F, Mukherjee B, Tayob N, Wang F, Sparr J, Raymond VM, Bandipalliam P, Stoffel EM, Gruber SB and Syngal S: Risk of pancreatic cancer in families with Lynch syndrome. JAMA 302: 1790-1795, 2009.

26. Moskaluk CA, Hruban H, Lietman A, Smyrk T, Fusaro L, Fusaro R, Lynch J, Yeo CJ, Jackson CE, Lynch HT and Kern SE: Novel germline p16(INK4) allele (Asp145Cys) in a family with multiple pancreatic carcinomas. Mutations in brief no. 148 Online. Hum Mutat 12: 70, 1998

27. Vasen HF, Gruis NA, Frants RR, van Der Velden PA, Hille ET and Bergman W: Risk of developing pancreatic cancer in families with familial atypical multiple mole melanoma associated with a specific 19 deletion of p16 (p16-Leiden). Int J Cancer 87: 809-811, 2000.

28. Goldstein AM, Struewing JP, Fraser MC, Smith MW and Tucker MA: Prospective risk of cancer in CDKN2A germline mutation carriers. J Med Genet 41: 421-424, 2004.

29. Rutter JL, Bromley CM, Goldstein AM, Elder DE, Holly EA, Guerry D IV, Hartge P, Struewing JP, Hogg D, Halpern A, et al: Heterogeneity of risk for melanoma and pancreatic and digestive malignancies: A melanoma case-control study. Cancer 101: 2809-2816, 2004.

30. Mizrahi JD, Surana R, Valle JW and Shroff RT: Pancreatic cancer. Lancet 395: 2008-2020, 2020.

31. Iacobuzio-Donahue CA: Genetic evolution of pancreatic cancer: Lessons learnt from the pancreatic cancer genome sequencing project. Gut 61: 1085-1094, 2012

32. Noë M, Rezaee N, Asrani K, Skaro M, Groot VP, Wu PH, Olson MT, Hong SM, Kim SJ, Weiss MJ, et al: Immunolabeling of cleared human pancreata provides insights into threedimensional pancreatic anatomy and pathology. Am J Pathol 188: $1530-1535,2018$.

33. Yamada M, Sugiura T, Okamura Y, Ito T, Yamamoto Y, Ashida R, Sasaki K, Nagino M and Uesaka K: Microscopic venous invasion in pancreatic cancer. Ann Surg Oncol 25: 1043-1051, 2018.

34. Costa-Silva B, Aiello NM, Ocean AJ, Singh S, Zhang H, Thakur BK, Becker A, Hoshino A, Mark MT, Molina H, et al: Pancreatic cancer exosomes initiate pre-metastatic niche formation in the liver. Nat Cell Biol 17: 816-826, 2015.

35. Fidler IJ and Poste G: The 'seed and soil' hypothesis revisited. Lancet Oncol 9: 808, 2008.

36. Wang S, Zheng Y, Yang F, Zhu L, Zhu XQ, Wang ZF, Wu XL, Zhou CH, Yan JY, Hu BY, et al: The molecular biology of pancreatic adenocarcinoma: Translational challenges and clinical perspectives. Signal Transduct Target Ther 6: 249, 2021.
37. Campbell PJ, Yachida S, Mudie LJ, Stephens PJ, Pleasance ED, Stebbings LA, Morsberger LA, Latimer C, McLaren S, Lin ML, et al: The patterns and dynamics of genomic instability in metastatic pancreatic cancer. Nature 467: 1109-1113, 2010.

38. Chan-Seng-Yue M, Kim JC, Wilson GW, Ng K, Figueroa EF, O'Kane GM, Connor AA, Denroche RE, Grant RC, McLeod J, et al: Transcription phenotypes of pancreatic cancer are driven by genomic events during tumor evolution. Nat Genet 52: 231-240, 2020.

39. Hruban RH, Gaida MM, Thompson E, Hong SM, Noë M, Brosens LA, Jongepier M, Offerhaus GJA and Wood LD: Why is pancreatic cancer so deadly? The Pathologist's view. J Pathol 248: 131-141, 2019.

40. Cancer Genome Atlas Research Network. Electronic address: andrew_aguirre@dfci.harvard.edu and Cancer Genome Atlas Research Network: Integrated genomic characterization of pancreatic ductal adenocarcinoma. Cancer Cell 32: 185-203.e13, 2017.

41. Hidalgo M: Pancreatic cancer. N Engl J Med 362: 1605-1617, 2010.

42. National Comprehensive Cancer Network: NCCN Clinical Practice Guidelines in Oncology (NCCN Guidelines) Pancreatic Adenocarcinoma. Version 1.2020, November 26, 2019.

43. Lambert A, Schwarz L, Borbath I, Henry A, Van Laethem JL, Malka D, Ducreux M and Conroy T: An update on treatment options for pancreatic adenocarcinoma. Ther Adv Med Oncol 11: $1758835919875568,2019$.

44. Devisetty $\mathrm{K}$ and Wong SJ: Neoadjuvant versus induction chemotherapy: More than semantics. J Clin Oncol 31: 2971-2972, 2013.

45. NIH-National Cancer Institute: NCI Dictionary of Cancer Terms. Available from: http://wwwcancergov/dictionary. Accessed September 27, 2021.

46. National Comprehensive Cancer Network: NCCN Clinical Practice Guidelines in Oncology (NCCN Guidelines) Pancreatic Adenocarcinoma Version 2.0 2021-February 25, 2021. wwwnccnorg, 2021.

47. Napolitano F, Formisano L, Giardino A, Girelli R, Servetto A, Santaniello A, Foschini F, Marciano R, Mozzillo E, Carratù $\mathrm{AC}$, et al: Neoadjuvant treatment in locally advanced pancreatic cancer (LAPC) patients with FOLFIRINOX or gemcitabine NabPaclitaxel: A single-center experience and a literature review. Cancers (Basel) 11: 981, 2019.

48. Macedo FI, Ryon E, Maithel SK, Lee RM, Kooby DA, Fields RC, Hawkins WG, Williams G, Maduekwe U, Kim HJ, et al: Survival outcomes associated with clinical and pathological response following neoadjuvant FOLFIRINOX or gemcitabine/Nab-paclitaxel chemotherapy in resected pancreatic cancer. Ann Surg 270: 400-413, 2019.

49. Ghaneh P, Palmer DH, Cicconi S, Halloran C, Psarelli E, Rawcliffe C, Sripadam R, Mukherjee S, Wadsley J, Al-Mukhtar A, et al: ESPAC-5F: Four-arm, prospective, multicenter, international randomized phase II trial of immediate surgery compared with neoadjuvant gemcitabine plus capecitabine (GEMCAP) or FOLFIRINOX or chemoradiotherapy (CRT) in patients with borderline resectable pancreatic cancer. J Clin Oncol 38: 4505-4505, 2020.

50. Truty MJ, Kendrick ML, Nagorney DM, Smoot RL, Cleary SP, Graham RP, Goenka AH, Hallemeier CL, Haddock MG, Harmsen WS, et al: Factors predicting response, perioperative outcomes, and survival following total neoadjuvant therapy for Borderline/locally advanced pancreatic cancer. Ann Surg 273: 341-349, 2021.

51. Kaufmann B, Hartmann D, D'Haese JG, Stupakov P, Radenkovic D, Gloor B and Friess H: Neoadjuvant treatment for borderline resectable pancreatic ductal adenocarcinoma. Dig Surg 36: 455-461, 2019.

52. Hammel P, Huguet F, van Laethem JL, Goldstein D, Glimelius B, Artru P, Borbath I, Bouché O, Shannon J, André T, et al: Effect of chemoradiotherapy vs chemotherapy on survival in patients with locally advanced pancreatic cancer controlled after 4 months of gemcitabine with or without erlotinib: The LAP07 randomized clinical trial. JAMA 315: 1844-1853, 2016.

53. Hammel P, Lacy J, Portales F, Sobrero AF, Pazo Cid RA, Mozo JLM, Terrebonne E, Dowden SD, Li JS, Ong TJ, et al: Phase II LAPACT trial of nab-paclitaxel (nab-P) plus gemcitabine (G) for patients with locally advanced pancreatic cancer (LAPC). J Clin Oncol 36: 204, 2018. 
54. Hurt CN, Falk S, Crosby T, McDonald A, Ray R, Joseph G, Staffurth J, Abrams RA, Griffiths G, Maughan T and Mukherjee S: Long-term results and recurrence patterns from SCALOP: A phase II randomised trial of gemcitabine- or capecitabine-based chemoradiation for locally advanced pancreatic cancer. Br J Cancer 116: 1264-1270, 2017.

55. Mukherjee S, Hurt CN, Bridgewater J, Falk S, Cummins S, Wasan H, Crosby T, Jephcott C, Roy R, Radhakrishna G, et al: Gemcitabine-based or capecitabine-based chemoradiotherapy for locally advanced pancreatic cancer (SCALOP): A multicentre, randomised, phase 2 trial. Lancet Oncol 14: 317-326, 2013.

56. Pietrasz D, Turrini O, Vendrely V, Simon JM, Hentic O, Coriat R, Portales F, Le Roy B, Taieb J, Regenet N, et al: How does chemoradiotherapy following induction FOLFIRINOX improve the results in resected borderline or locally advanced pancreatic adenocarcinoma? An AGEO-FRENCH multicentric cohort. Ann Surg Oncol 26: 109-117, 2019.

57. Katz MH, Ou FS, Herman JM, Ahmad SA, Wolpin B, Marsh R, Behr S, Shi Q, Chuong M, Schwartz LH, et al: Alliance for clinical trials in oncology (ALLIANCE) trial A021501: Preoperative extended chemotherapy vs. chemotherapy plus hypofractionated radiation therapy for borderline resectable adenocarcinoma of the head of the pancreas. BMC Cancer 17: 505, 2017.

58. Zhong J, Patel K, Switchenko J, Cassidy RJ, Hall WA, Gillespie T, Patel PR, Kooby D and Landry J: Outcomes for patients with locally advanced pancreatic adenocarcinoma treated with stereotactic body radiation therapy versus conventionally fractionated radiation. Cancer 123: 3486-3493, 2017.

59. Sohal DP, Kennedy EB, Khorana A, Copur MS, Crane CH, Garrido-Laguna I, Krishnamurthi S, Moravek C, O'Reilly EM Philip PA, et al: Metastatic pancreatic cancer: ASCO clinical practice guideline update. J Clin Oncol 36: 2545-2556, 2018.

60. Oken MM, Creech RH, Tormey DC, Horton J, Davis TE, McFadden ET and Carbone PP: Toxicity and response criteria of the Eastern Cooperative Oncology Group. Am J Clin Oncol 5 649-655, 1982

61. Sultana A, Tudur Smith C, Cunningham D, Starling N, Neoptolemos JP and Ghaneh P: Meta-analyses of chemotherapy for locally advanced and metastatic pancreatic cancer: Results of secondary end points analyses. Br J Cancer 99: 6-13, 2008.

62. Burris HA III, Moore MJ, Andersen J, Green MR, Rothenberg ML, Modiano MR, Cripps MC, Portenoy RK, Storniolo AM, Tarassoff $\mathrm{P}$, et al: Improvements in survival and clinical benefit with gemcitabine as first-line therapy for patients with advanced pancreas cancer: A randomized trial. J Clin Oncol 15: 2403-2413, 1997.

63. Moore MJ, Goldstein D, Hamm J, Figer A, Hecht JR, Gallinger S, Au HJ, Murawa P, Walde D, Wolff RA, et al: Erlotinib plus gemcitabine compared with gemcitabine alone in patients with advanced pancreatic cancer: A phase III trial of the National Cancer Institute of Canada Clinical Trials Group. J Clin Oncol 25: 1960-1966, 2007.

64. Ciliberto D, Botta C, Correale P, Rossi M, Caraglia M, Tassone P and Tagliaferri P: Role of gemcitabine-based combination therapy in the management of advanced pancreatic cancer: A meta-analysis of randomised trials. Eur J Cancer 49: 593-603, 2013.

65. Conroy T, Desseigne F, Ychou M, Bouché O, Guimbaud R, Bécouarn Y, Adenis A, Raoul JL, Gourgou-Bourgade S, de la Fouchardière $\mathrm{C}$, et al: FOLFIRINOX versus gemcitabine for metastatic pancreatic cancer. N Engl J Med 364: 1817-1825, 2011.

66. Von Hoff DD, Ervin T, Arena FP, Chiorean EG, Infante J, Moore M, Seay T, Tjulandin SA, Ma WW, Saleh MN, et al: Increased survival in pancreatic cancer with nab-paclitaxel plus gemcitabine. N Engl J Med 369: 1691-1703, 2013.

67. Pusceddu S, Ghidini M, Torchio M, Corti F, Tomasello G Niger M, Prinzi N, Nichetti F, Coinu A, Di Bartolomeo M, et al: Comparative effectiveness of gemcitabine plus nab-Paclitaxel and FOLFIRINOX in the First-Line setting of metastatic pancreatic cancer: A systematic review and Meta-Analysis. cancers (Basel) 11: 484, 2019.

68. Ueno H, Ioka T, Ikeda M, Ohkawa S, Yanagimoto H, Boku N, Fukutomi A, Sugimori K, Baba H, Yamao K, et al: Randomized phase III study of gemcitabine plus S-1, S-1 alone, or gemcitabine alone in patients with locally advanced and metastatic pancreatic cancer in Japan and Taiwan: GEST study. J Clin Oncol 31: 1640-1648, 2013.
69. Zong Y, Yuan J, Peng Z, Lu M, Wang X, Shen L and Zhou J: Nab-paclitaxel plus S-1 versus nab-paclitaxel plus gemcitabine as first-line chemotherapy in patients with advanced pancreatic ductal adenocarcinoma: A randomized study. J Cancer Res Clin Oncol 147: 1529-1536, 2021.

70. Ducreux M, Cuhna AS, Caramella C, Hollebecque A, Burtin P, Goéré D, Seufferlein T, Haustermans K, Van Laethem JL, Conroy T, et al: Cancer of the pancreas: ESMO Clinical Practice Guidelines for diagnosis, treatment and follow-up. Ann Oncol 26 (Suppl 5): v56-v68, 2015.

71. Sohal DP, Mangu PB, Khorana AA, Shah MA, Philip PA, O'Reilly EM, Uronis HE, Ramanathan RK, Crane $\mathrm{CH}$, Engebretson A, et al: Metastatic pancreatic cancer: American society of clinical oncology clinical practice guideline. J Clin Oncol 34: 2784-2796, 2016.

72. Ghosn M, Saroufim A, Kattan J, Chahine G, Nasr F and Farhat F: Sequential FOLFOX-6 and gemcitabine for locally advanced and/or metastatic pancreatic cancer. Med Oncol 29: 2831-2837, 2012.

73. Dahan L, Phelip JM, Malicot KL, Williet N, Desrame J, Volet J, Petorin C, Malka D, Rebischung C, Aparicio T, et al: FOLFIRINOX until progression, FOLFIRINOX with maintenance treatment, or sequential treatment with gemcitabine and FOLFIRI.3 for first-line treatment of metastatic pancreatic cancer: A randomized phase II trial (PRODIGE 35-PANOPTIMOX) 2018 ASCO Annual Meeting I Gastrointestinal (noncolorectal). J Clin Oncol 36: 4000, 2018.

74. International Society of Geriatric Oncology: Population Demographics-Cancer Epidemiology, 2021.

75. GBD 2017 Pancreatic Cancer Collaborators: The global, regional, and national burden of pancreatic cancer and its attributable risk factors in 195 countries and territories, 1990-2017: A systematic analysis for the Global Burden of Disease Study 2017. Lancet Gastroenterol Hepatol 4: 934-947, 2019.

76. Lamont EB, Schilsky RL, He Y, Muss H, Cohen HJ, Hurria A, Meilleur A, Kindler HL, Venook A, Lilenbaum R, et al: Generalizability of trial results to elderly Medicare patients with advanced solid tumors (Alliance 70802). J Natl Cancer Inst 107: 336, 2015.

77. Higuera O, Ghanem I, Nasimi R, Prieto I, Koren L and Feliu J: Management of pancreatic cancer in the elderly. World J Gastroenterol 22: 764-775, 2016.

78. Petrillo A, Pappalardo A, Calabrese F, Tirino G, Pompella L, Ventriglia J, Laterza MM, Caterino M, Sforza V, Iranzo V, et al: First line nab-paclitaxel plus gemcitabine in elderly metastatic pancreatic patients: A good choice beyond age. J Gastrointest Oncol 10: 910-917, 2019.

79. Martin JL, Sidhu S, Benhayoun N, Dedonno M and Brenner WS: Dosing modifications to increase tolerability of gemcitabine and nab-paclitaxel in treatment of pancreatic cancer in the elderly. J Clin Oncol 37: 441, 2019.

80. Li D, Capanu M, Yu KH, Lowery MA, Kelsen DP and O'Reilly EM: Treatment, outcomes, and clinical trial participation in elderly patients with metastatic pancreas adenocarcinoma. Clin Colorectal Cancer 14: 269-276.e1, 2015.

81. Guion-Dusserre JF, Bertaut A, Ghiringhelli F, Vincent J, Quipourt V, Marilier S, Tharin Z and Bengrine-Lefevre L: Folfirinox in elderly patients with pancreatic or colorectal cancertolerance and efficacy. World J Gastroenterol 22: 9378-9386, 2016.

82. Yamamoto T, Sunakawa Y, Kubota Y, Tagawa T, Kaga Y, Uto TIY, Kitahara Y, Toshima H, Kobayashi K, Kitahara A, et al: Tolerability and clinical outcomes in elderly patients with advanced pancreatic cancer treated with FOLFIRINOX. J Clin Oncol 34: 404, 2016.

83. Alessandretti MB, Moreira RB, Brandao EP, Gomes JR, Amarante PM, Junior A de RL, Abrahao CM de Sousa TT, de Sousa AD, Cruz MR, Maluf FC and Buzaid AC: Safety and efficacy of modified dose-attenuated FOLFIRINOX chemotherapy in patients over 65 years with advanced pancreatic adenocarcinoma. J Clin Oncol 33: 468, 2015.

84. Michalaki V, Poydorou A, Vezakis A, Frangulidis G, Theodosopoulos T and Papadimitriou C: Gemcitabine plus capecitabine in elderly patients with advanced pancreatic cancer. Ann Oncol 28: iii76, 2017.

85. Marsanic P, Mellano A, Sottile A and De Simone M: Irreversible electroporation as treatment of locally advanced and as margin accentuation in borderline resectable pancreatic adenocarcinoma. Med Biol Eng Comput 55: 1123-1127, 2017.

86. Sohal DP, Kennedy EB, Cinar P, Conroy T, Copur MS, Crane CH, Garrido-Laguna I, Lau MW, Johnson T, Krishnamurthi S, et al: Metastatic pancreatic cancer: ASCO guideline update. J Clin Oncol:Aug 5,2020(Epubahead of print).doi: 10.1200/JCO.20.01364. 
87. Macarulla T, Pazo-Cid R, Guillén-Ponce C, López R, Vera R, Reboredo M, Muñoz Martin A, Rivera F, Díaz Beveridge R, La Casta A, et al: Phase I/II Trial to evaluate the efficacy and safety of nanoparticle albumin-bound paclitaxel in combination with gemcitabine in patients with pancreatic cancer and an ECOG performance status of 2. J Clin Oncol 37: 230-238, 2019.

88. Cunningham D, Chau I, Stocken DD, Valle JW, Smith D, Steward W, Harper PG, Dunn J, Tudur-Smith C, West J, et al: Phase III randomized comparison of gemcitabine versus gemcitabine plus capecitabine in patients with advanced pancreatic cancer. J Clin Oncol 27: 5513-5518, 2009.

89. Smith AL, Wong C, Cuggia A, Borgida A, Holter S, Hall A, Connor AA, Bascuñana C, Asselah J, Bouganim N, et al: Reflex Testing for Germline BRCA1, BRCA2, PALB2, and ATM mutations in pancreatic cancer: Mutation prevalence and clinical outcomes from two canadian research registries. JCO Precision Oncology: Jan 19, 2018 doi: 10.1200/PO.17.00098.

90. Gudmundsdottir K and Ashworth A: The roles of BRCA1 and BRCA2 and associated proteins in the maintenance of genomic stability. Oncogene 25: 5864-5874, 2006.

91. Rebelatto TF, Falavigna M, Pozzari M, Pozzari M, Spada F, Cella CA, Laffi A, Pellicori S and Fazio N: Should platinum-based chemotherapy be preferred for germline BReast CAncer genes (BRCA) 1 and 2-mutated pancreatic ductal adenocarcinoma (PDAC) patients? A systematic review and meta-analysis. Cancer Treat Rev 80: 101895, 2019.

92. Stoffel EM, McKernin SE, Brand R, Canto M, Goggins M, Moravek C, Nagarajan A, Petersen GM, Simeone DM, Yurgelun $\mathrm{M}$ and Khorana AA: Evaluating susceptibility to pancreatic cancer: ASCO provisional clinical opinion. J Clin Oncol 37: 153-164, 2019.

93. National Comprehensive Cancer Network: NCCN Clinical Practice Guidelines in Oncology (NCCN Guidelines) Pancreatic Adenocarcinoma. Version 1.2021. October 23, 2020.

94. Golan T, Hammel P, Reni M, Van Cutsem E, Macarulla T, Hall MJ, Park JO, Hochhauser D, Arnold D, Oh DY, et al: Maintenance olaparib for germline BRCA-mutated metastatic pancreatic cancer. N Engl J Med 381: 317-327, 2019.

95. Hammel P, Kindler HL, Reni M, Van Cutsem E, Macarulla T, Hall MJ, Park JO, Hochhauser D, Arnold D, Oh DY, et al Health-related quality of life in patients with a germline BRCA mutation and metastatic pancreatic cancer receiving maintenance olaparib. Ann Oncol 30: 1959-1968, 2019.

96. Golan T, Hammel P, Reni M, et al: Final overall survival results from the phase 3 POLO trial: Maintenance olaparib for germline BRCA-mutated metastatic pancreatic cancer. 2021 Gastrointestinal Cancer Symposium. Oral Presentation GI21 presented at ASCO-GI, 2021.

97. O'Reilly EM, Lee JW, Zalupski M, Capanu M, Park J, Golan T, Tahover E, Lowery MA, Chou JF, Sahai V, et al: Randomized, multicenter, phase ii trial of gemcitabine and cisplatin with or without veliparib in patients with pancreas adenocarcinoma and a germline BRCA/PALB2 mutation. J Clin Oncol 38: 1378-1388, 2020 .

98. Wattenberg MM, Asch D, Yu S, O'Dwyer PJ, Domchek SM, Nathanson KL, Rosen MA, Beatty GL, Siegelman ES and Reiss KA: Platinum response characteristics of patients with pancreatic ductal adenocarcinoma and a germline BRCA1, BRCA2 or PALB2 mutation. Br J Cancer 122: 333-339, 2020.

99. Nishikawa G, Booth C and Prasad V: Olaparib for BRCA mutant pancreas cancer: Should the POLO trial change clinical practice? Cancer 126: 4087-4088, 2020.

100. Rahma OE, Duffy A, Liewehr DJ, Steinberg SM and Greten TF: Second-line treatment in advanced pancreatic cancer: A comprehensive analysis of published clinical trials. Ann Oncol 24: 1972-1979, 2013.

101. Lee K, Bang K, Yoo C, Hwang I, Jeong JH, Chang HM, Oh D, Song TJ, Park DH, Lee SS, et al: Clinical outcomes of second-line chemotherapy after progression on Nab-paclitaxel plus gemcitabine in patients with metastatic pancreatic adenocarcinoma. Cancer Res Treat 52: 254-262, 2020.

102. Sonbol MB, Firwana B, Wang Z, Almader-Douglas D, Borad MJ, Makhoul I, Ramanathan RK, Ahn DH and Bekaii-Saab T: Second-line treatment in patients with pancreatic ductal adenocarcinoma: A meta-analysis. Cancer 123: 4680-4686, 2017.

103. Cherri S, Noventa S and Zaniboni A: Pancreatic adenocarcinoma: Beyond first line, where are we? World J Gastroenterol 27: 1847-1863, 2021.
104. Oettle H, Riess H, Stieler JM, Heil G, Schwaner I, Seraphin J, Görner M, Mölle M, Greten TF, Lakner V, et al: Second-line oxaliplatin, folinic acid, and fluorouracil versus folinic acid and fluorouracil alone for gemcitabine-refractory pancreatic cancer: Outcomes from the CONKO-003 trial. J Clin Oncol 32: 2423-2429, 2014

105. Gill S, Ko YJ, Cripps C, Beaudoin A, Dhesy-Thind S, Zulfiqar M, Zalewski P, Do T, Cano P, Lam WYH, et al: PANCREOX: A randomized phase III study of Fluorouracil/Leucovorin with or without oxaliplatin for second-line advanced pancreatic cancer in patients who have received gemcitabine-based chemotherapy. J Clin Oncol 34: 3914-3920, 2016.

106. Xiong HQ, Varadhachary GR, Blais JC, Hess KR, Abbruzzese JL and Wolff RA: Phase 2 trial of oxaliplatin plus capecitabine (XELOX) as second-line therapy for patients with advanced pancreatic cancer. Cancer 113: 2046-2052, 2008.

107. Ohkawa S, Okusaka T, Isayama H, Fukutomi A, Yamaguchi K, Ikeda M, Funakoshi A, Nagase M, Hamamoto Y, Nakamori S, et al: Randomised phase II trial of S-1 plus oxaliplatin vs $\mathrm{S}-1$ in patients with gemcitabine-refractory pancreatic cancer. Br J Cancer 112: 1428-1434, 2015.

108. Fortune BE, Li X, Kosuri KV, Weatherby LM, Thomas JP and Bekaii-Saab TS: Fixed-dose-rate gemcitabine in combination with oxaliplatin in patients with metastatic pancreatic cancer refractory to standard-dose-rate gemcitabine: A single-institute study. Oncology 76: 333-337, 2009.

109. Demols A, Peeters M, Polus M, Marechal R, Gay F, Monsaert E, Hendlisz A and Van Laethem JL: Gemcitabine and oxaliplatin (GEMOX) in gemcitabine refractory advanced pancreatic adenocarcinoma: A phase II study. Br J Cancer 94: 481-485, 2006.

110. Ramfidis VS, Syrigos KN and Saif MW: New therapeutic strategies in the second line setting of advanced or metastatic pancreatic adenocarcinoma. JOP 14: 344-346, 2013.

111. Portal A, Pernot S, Tougeron D, Arbaud C, Bidault AT, de la Fouchardière C, Hammel P, Lecomte T, Dréanic J, Coriat $\mathrm{R}$, et al: Nab-paclitaxel plus gemcitabine for metastatic pancreatic adenocarcinoma after Folfirinox failure: An AGEO prospective multicentre cohort. Br J Cancer 113: 989-995, 2015.

112. Le DT, Durham JN, Smith KN, Wang H, Bartlett BR, Aulakh LK, Lu S, Kemberling H, Wilt C, Luber BS, et al: Mismatch repair deficiency predicts response of solid tumors to PD-1 blockade. Science 357: 409-413, 2017.

113. Le DT, Uram JN, Wang H, Bartlett BR, Kemberling H, Eyring AD, Skora AD, Luber BS, Azad NS, Laheru D, et al: PD-1 Blockade in tumors with mismatch-repair deficiency. N Engl J Med 372: 2509-2520, 2015.

114. Marabelle A, Le DT, Ascierto PA, Di Giacomo AM, De Jesus-Acosta A, Delord JP, Geva R, Gottfried M, Penel N, Hansen AR, et al: Efficacy of pembrolizumab in patients with noncolorectal high microsatellite Instability/Mismatch Repair-deficientcancer:Results from the phaseIIKEYNOTE-158 study. J Clin Oncol 38: 1-10, 2020.

115. Bockorny B, Semenisty V,Macarulla T, BorazanciE, Wolpin BM, Stemmer SM, Golan T, Geva R, Borad MJ, Pedersen KS, et al: BL-8040, a CXCR4 antagonist, in combination with pembrolizumab and chemotherapy for pancreatic cancer: The COMBAT trial. Nat Med 26: 878-885, 2020

116. Okamura R, Boichard A, Kato S, Sicklick JK, Bazhenova L and Kurzrock R: Analysis of NTRK alterations in pan-cancer adult and pediatric malignancies: Implications for NTRK-Targeted therapeutics. JCO Precis Oncol 2018: PO.18.00183, 2018.

117. Solomon JP, Linkov I, Rosado A, Mullaney K, Rosen EY, Frosina D, Jungbluth AA, Zehir A, Benayed R, Drilon A, et al: NTRK fusion detection across multiple assays and 33,997 cases: Diagnostic implications and pitfalls. Mod Pathol 33: 38-46, 2020.

118. O'Reilly EM and Hechtman JF: Tumour response to TRK inhibition in a patient with pancreatic adenocarcinoma harbouring an NTRK gene fusion. Ann Oncol 30 (Suppl 8): viii36-viii40, 2019

119. Doebele RC, Drilon A, Paz-Ares L, Siena S, Shaw AT, Farago AF, Blakely CM, Seto T, Cho BC, Tosi D, et al: Entrectinib in patients with advanced or metastatic NTRK fusion-positive solid tumours: Integrated analysis of three phase 1-2 trials. Lancet Oncol 21: 271-282, 2020.

120. Wang-Gillam A, Hubner RA, Siveke JT, Von Hoff DD, Belanger B, de Jong FA, Mirakhur B and Chen LT: NAPOLI-1 phase 3 study of liposomal irinotecan in metastatic pancreatic cancer: Final overall survival analysis and characteristics of long-term survivors. Eur J Cancer 108: 78-87, 2019. 
121. Humphris JL, Patch AM, Nones K, Bailey PJ, Johns AL, McKay S, Chang DK, Miller DK, Pajic M, Kassahn KS, et al: Hypermutation in pancreatic cancer. Gastroenterology 152 68-74.e2, 2017.

122. Leem G and Song SY: Immunotherapy in pancreatic cancer; the road less traveled. Immunol Disord Immunother 1: 106, 2016.

123. Hayashi A, Hong J and Iacobuzio-Donahue CA: The pancreatic cancer genome revisited. Nat Rev Gastroenterol Hepatol 18 469-481, 2021.

124. Nedaeinia R, Avan A, Manian M, Salehi R and GhayourMobarhan M: EGFR as a potential target for the treatment of pancreatic cancer: Dilemma and controversies. Curr Drug Targets 15: 1293-1301, 2014.

125. Navas C, Hernández-Porras I, Schuhmacher AJ, Sibilia M, Guerra $\mathrm{C}$ and Barbacid M: EGF receptor signaling is essential for k-ras oncogene-driven pancreatic ductal adenocarcinoma. Cancer Cell 22: 318-330, 2012.

126. Matsuoka T and Yashiro M: Molecular targets for the treatment of pancreatic cancer: Clinical and experimental studies. World J Gastroenterol 22: 776-789, 2016.

127. Nywening TM, Wang-Gillam A, Sanford DE, Belt BA, Panni RZ, Cusworth BM, Toriola AT, Nieman RK, Worley LA, Yano M, et al: Targeting tumour-associated macrophages with CCR2 inhibition in combination with FOLFIRINOX in patients with borderline resectable and locally advanced pancreatic cancer: A single-centre, open-label, dose-finding, non-randomised, phase 1b trial. Lancet Oncol 17: 651-662, 2016.

128. Kamerkar S, LeBleu VS, Sugimoto H, Yang S, Ruivo CF, Melo SA, Lee JJ and Kalluri R: Exosomes facilitate therapeutic targeting of oncogenic KRAS in pancreatic cancer. Nature 546: 498-503, 2017.

129. ClinicalTrials gov: National Library of Medicine (US) 2000 Feb 29: Identifier NCT03608631, iExosomes in Treating Participants with Metastatic Pancreas Cancer with KrasG12D Mutation. August 1, 2018 [cited 2020 June 29]. Bethesda, MD, 2020. Available from: https://clinicaltrials. gov/ct2/show/NCT03608631.

130. Garrido-Laguna I, Uson M, Rajeshkumar NV, Tan AC, de Oliveira E, Karikari C, Villaroel MC, Salomon A, Taylor G, Sharma R, et al: Tumor engraftment in nude mice and enrichment in stroma- related gene pathways predict poor survival and resistance to gemcitabine in patients with pancreatic cancer. Clin Cancer Res 17: 5793-5800, 2011.

131. Yachida S and Iacobuzio-Donahue CA: The pathology and genetics of metastatic pancreatic cancer. Arch Pathol Lab Med 133: 413-422, 2009

132. Olive KP, Jacobetz MA, Davidson CJ, Gopinathan A, McIntyre D, Honess D, Madhu B, Goldgraben MA, Caldwell ME, Allard D, et al: Inhibition of Hedgehog signaling enhances delivery of chemotherapy in a mouse model of pancreatic cancer. Science 324: 1457-1461, 2009.

133. Provenzano PP, Cuevas C, Chang AE, Goel VK, Von Hoff DD and Hingorani SR: Enzymatic targeting of the stroma ablates physical barriers to treatment of pancreatic ductal adenocarcinoma. Cancer Cell 21: 418-429, 2012.

134. Sherman MH, Yu RT, Engle DD, Ding N, Atkins AR, Tiriac H Collisson EA, Connor F, Van Dyke T, Kozlov S, et al: Vitamin D receptor-mediated stromal reprogramming suppresses pancreatitis and enhances pancreatic cancer therapy. Cell 159: 80-93, 2014

135. van Duijnhoven FJB, Jenab M, Hveem K, Siersema PD, Fedirko V, Duell EJ, Kampman E, Halfweeg A, van Kranen HJ, van den Ouweland JM, et al: Circulating concentrations of vitamin $\mathrm{D}$ in relation to pancreatic cancer risk in European populations. Int J Cancer 142: 1189-1201, 2018.
136. Gorchs L, Ahmed S, Mayer C, Knauf A, Fernández Moro C, Svensson M, Heuchel R, Rangelova E, Bergman P and Kaipe H: The vitamin $\mathrm{D}$ analogue calcipotriol promotes an antitumorigenic phenotype of human pancreatic CAFs but reduces T cell mediated immunity. Sci Rep 10: 17444, 2020.

137. Le Large TY, Bijlsma MF, Kazemier G, van Laarhoven HW, Giovannetti E and Jimenez CR: Key biological processes driving metastatic spread of pancreatic cancer as identified by multi-omics studies. Semin Cancer Biol 44: 153-169, 2017.

138. Sano M, Ijichi H, Takahashi R, Miyabayashi K, Fujiwara $H$, Yamada T, Kato H, Nakatsuka T, Tanaka Y, Tateishi K, et al: Blocking CXCLs-CXCR2 axis in tumor-stromal interactions contributes to survival in a mouse model of pancreatic ductal adenocarcinoma through reduced cell invasion/migration and a shift of immune-inflammatory microenvironment. Oncogenesis 8: 8, 2019.

139. Pishvaian MJ, Rolfo CD, Liu SV, Multani PS, Maneval EC and Garrido-Laguna I: Clinical benefit of entrectinib for patients with metastatic pancreatic cancer who harbor NTRK and ROS1 fusions. J Clin Oncol 36: 521, 2018.

140. Drilon A, Siena S, Ou SI, Patel M, Ahn MJ, Lee J, Bauer TM, Farago AF, Wheler JJ, Liu SV, et al: Safety and antitumor activity of the multitargeted Pan-TRK, ROS1, and ALK inhibitor entrectinib: Combined results from two phase I trials (ALKA-372-001 and STARTRK-1). Cancer Discov 7: 400-409, 2017.

141. Yan HH, Jung KH, Son MK, Fang Z, Kim SJ, Ryu YL, Kim J, Kim MH and Hong SS: Crizotinib exhibits antitumor activity by targeting ALK signaling not c-MET in pancreatic cancer. Oncotarget 5: 9150-9168, 2014.

142. Herreros-Villanueva M and Bujanda L: Non-invasive biomarkers in pancreatic cancer diagnosis: What we need versus what we have. Ann Transl Med 4: 134, 2016.

143. Humphris JL, Chang DK, Johns AL, Scarlett CJ, Pajic M, Jones MD, Colvin EK, Nagrial A, Chin VT, Chantrill LA, et al: The prognostic and predictive value of serum CA19.9 in pancreatic cancer. Ann Oncol 23: 1713-1722, 2012.

144. Zhang Y, Yang J, Li H, Wu Y, Zhang H and Chen W: Tumor markers CA19-9, CA242 and CEA in the diagnosis of pancreatic cancer: A meta-analysis. Int J Clin Exp Med 8: 11683-11691, 2015.

145. Kaur S, Baine MJ, Jain M, Sasson AR and Batra SK: Early diagnosis of pancreatic cancer: Challenges and new developments. Biomark Med 6: 597-612, 2012.

146. Locker GY, Hamilton S, Harris J, Jessup JM, Kemeny N, Macdonald JS, Somerfield MR, Hayes DF and Bast RC Jr; ASCO: ASCO 2006 update of recommendations for the use of tumor markers in gastrointestinal cancer. J Clin Oncol 24: 5313-5327, 2006.

147. Goonetilleke KS and Siriwardena AK: Systematic review of carbohydrate antigen (CA 19-9) as a biochemical marker in the diagnosis of pancreatic cancer. Eur J Surg Oncol 33: 266-270, 2007.

148. Ruivo CF, Adem B, Silva M and Melo SA: The biology of cancer exosomes: Insights and new perspectives. Cancer Res 77: 6480-6488, 2017.

149. Melo SA, Luecke LB, Kahlert C, Fernandez AF, Gammon ST, Kaye J, LeBleu VS, Mittendorf EA, Weitz J, Rahbari N, et al: Glypican-1 identifies cancer exosomes and detects early pancreatic cancer. Nature 523: 177-182, 2015.

150. Hu W, Liu C, Bi ZY, Zhou Q, Zhang H, Li LL, Zhang J, Zhu W, Song YY and Zhang F: Comprehensive landscape of extracellular vesicle-derived RNAs in cancer initiation, progression, metastasis and cancer immunology. Mol Cancer 19: 102, 2020.

This work is licensed under a Creative Commons Attribution-NonCommercial-NoDerivatives 4.0 International (CC BY-NC-ND 4.0) License. 